\title{
Land Surface Data Assimilation
}

\author{
Paul R. Houser, Gabriëlle J.M. De Lannoy, and Jeffrey P. Walker
}

\section{Introduction}

Accurate knowledge of spatial and temporal land surface storages and fluxes are essential for addressing a wide range of important, socially relevant science, education, application and management issues. Improved estimates of land surface conditions are directly applicable to agriculture, ecology, civil engineering, water resources management, rainfall-runoff prediction, atmospheric process studies, climate and weather prediction, and disaster management (Houser et al. 2004).

While in situ observational networks are improving, the only practical way to observe the land surface on continental to global scales is via satellite remote sensing. Though remote sensing can make spatially comprehensive measurements of various components of the land surface system, it cannot provide information on the entire system (e.g. deep moisture stores), and the measurements represent only a snapshot in time. Land surface process models may be used to continuously predict the temporal and spatial land system variations, but these predictions are often poor, due to model initialization, parameter and forcing errors, and inadequate model physics and/or resolution.

Thus, satellite observations provide an incomplete snapshot of land surface conditions, while models provide a continuous estimate of land surface conditions subject to the model's simplifications. Therefore, an attractive prospect is to combine the strengths of land surface models and observations (and minimize the weaknesses) to provide a superior land surface state estimate. This is the goal of land surface data assimilation.

Data assimilation is the application of recursive Bayesian estimation to combine current and past data in an explicit dynamical model, using the model's prognostic equations to provide time continuity and dynamic coupling amongst the fields (see chapters in Part I, Theory). Land surface data assimilation aims to utilize both our

P.R. Houser $(\bowtie)$

George Mason University, Fairfax, VA, USA

e-mail: phouser@gmu.edu 


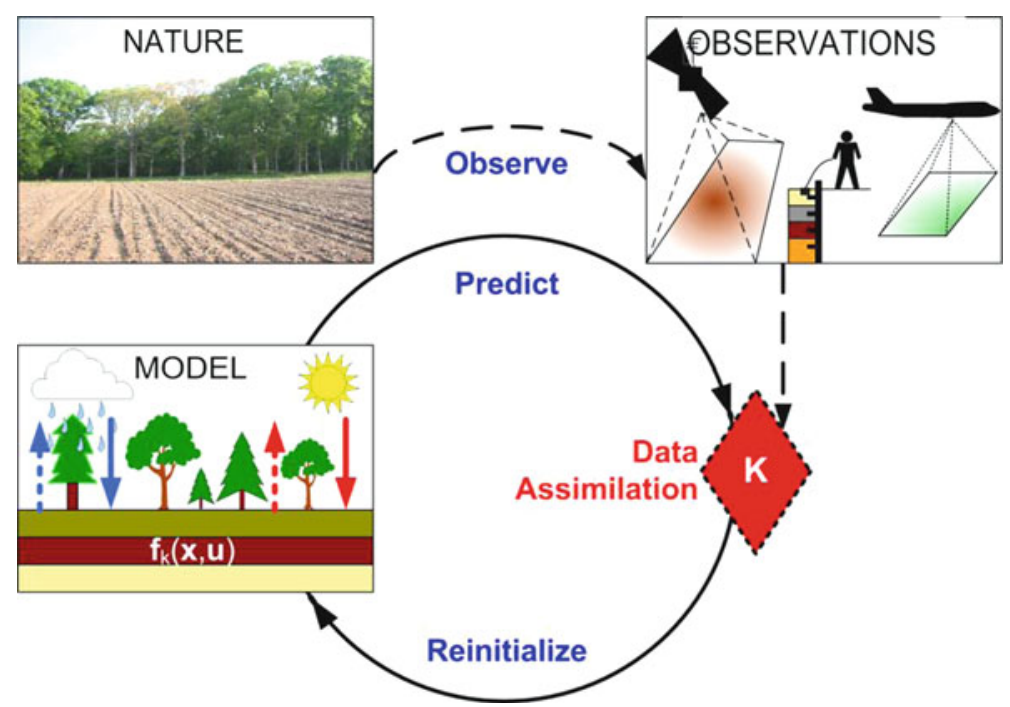

Fig. 1 Schematic description of the land surface data assimilation process

knowledge of land surface processes as embodied in a land surface model, and information that can be gained from observations, to produce an improved, continuous land surface state estimate in space and time.

Figure 1 illustrates the land surface data assimilation challenge to optimally merge the spatially comprehensive but limited remote sensing observations with the complete but typically poor predictions of a land surface model to yield the best possible hydrological system state estimation. Limited point measurements are often used to calibrate the model(s) and validate the assimilation results (Walker and Houser 2005).

\section{Background: Land Surface Observations}

Earth observing satellites have revolutionized our understanding and prediction of the Earth system over the last 3 decades, particularly in the meteorological and oceanographic sciences. However, historically, remote sensing data have not been widely used in land surface modelling and prediction. This can be attributed to: (i) a lack of dedicated land surface state (water and energy) remote sensing instruments; (ii) inadequate retrieval algorithms for deriving global land surface information from remote sensing observations; (iii) a lack of suitable distributed land surface models for digesting remote sensing information; and (iv) an absence of techniques to objectively improve and constrain land surface model predictions using remote sensing data. Four ways that remote sensing observations have been used in distributed land surface models are: (i) as parametric input data, including soil and land cover properties; (ii) as forcing input data, mainly precipitation, (iii) as initial condition data, 
such as initial snow water storage; and (iv) as time-varying land state data, such as soil moisture content, to constrain model predictions.

The historic lack of hydrological missions and observations has been the result of an emphasis on meteorological and oceanographic missions and applications, due to the large scientific and operational communities that drive those fields. However, significant progress has been made over the past decade on defining hydrologically-relevant remote sensing observations through focused ground and airborne field studies. Gradually, satellite-based hydrological data are becoming increasingly available, although little progress has been made in understanding their observational errors. Land surface skin temperature and snow cover data have been available for many years, and satellite precipitation data are becoming available at increasing space and time resolutions. In addition, land cover and land use maps, vegetation parameters (albedo, leaf area index, and greenness), and snow water equivalent data of increasing sophistication are becoming available from a number of sensors. Novel observations such as saturated fraction and changes in soil moisture, evapotranspiration, water level and velocity (i.e., runoff), and changes in total terrestrial water storage are also under development. Furthermore, near-surface soil moisture, a parameter shown to play a critical role in weather, climate, agriculture, flood, and drought processes, is currently available from non-ideal sensor configuration observations. Moreover, two missions targeted at measuring near-surface soil moisture with ideal sensor configuration are expected before the end of the decade (SMOS, SMAP; see Table 1).

Table 1 Characteristics of hydrological observations potentially available within the next decade (see Appendix for details of sensor acronyms)

\begin{tabular}{|c|c|c|c|c|c|}
\hline $\begin{array}{l}\text { Hydrological } \\
\text { quantity }\end{array}$ & $\begin{array}{l}\text { Remote sensing } \\
\text { technique }\end{array}$ & Time scale & Spatial scale & $\begin{array}{l}\text { Accuracy } \\
\text { considerations }\end{array}$ & $\begin{array}{l}\text { Examples } \\
\text { of sensors }\end{array}$ \\
\hline \multirow[t]{3}{*}{ Precipitation } & Thermal infrared & $\begin{array}{l}\text { Hourly } \\
1 \text { day } \\
15 \text { days }\end{array}$ & $\begin{array}{l}4 \mathrm{~km} \\
1 \mathrm{~km} \\
60 \mathrm{~m}\end{array}$ & $\begin{array}{l}\text { Tropical } \\
\text { convective } \\
\text { clouds only }\end{array}$ & $\begin{array}{l}\text { GOES, } \\
\text { MODIS, } \\
\text { AVHRR, } \\
\text { Landsat, } \\
\text { ASTER }\end{array}$ \\
\hline & $\begin{array}{l}\text { Passive } \\
\text { microwave }\end{array}$ & $3 \mathrm{~h}$ & $10 \mathrm{~km}$ & $\begin{array}{l}\text { Land } \\
\text { calibration } \\
\text { problems }\end{array}$ & $\begin{array}{l}\text { TRMM, } \\
\text { SSMI, } \\
\text { AMSR-E, } \\
\text { GPM }\end{array}$ \\
\hline & $\begin{array}{l}\text { Active } \\
\text { microwave }\end{array}$ & Daily & $10 \mathrm{~m}$ & $\begin{array}{l}\text { Land } \\
\text { calibration } \\
\text { problems }\end{array}$ & TRMM, GPM \\
\hline $\begin{array}{l}\text { Surface soil } \\
\text { moisture }\end{array}$ & $\begin{array}{l}\text { Passive } \\
\text { microwave }\end{array}$ & 1-3 days & $25-50 \mathrm{~km}$ & $\begin{array}{l}\text { Limited to } \\
\text { sparse } \\
\text { vegetation, } \\
\text { low } \\
\text { topographic } \\
\text { relief }\end{array}$ & $\begin{array}{c}\text { AMSR-E, } \\
\text { SMOS, } \\
\text { SMAP }\end{array}$ \\
\hline
\end{tabular}


Table 1 (continued)

\begin{tabular}{|c|c|c|c|c|c|}
\hline $\begin{array}{l}\text { Hydrological } \\
\text { quantity }\end{array}$ & $\begin{array}{l}\text { Remote sensing } \\
\text { technique }\end{array}$ & Time scale & Spatial scale & $\begin{array}{l}\text { Accuracy } \\
\text { considerations }\end{array}$ & $\begin{array}{l}\text { Examples } \\
\text { of sensors }\end{array}$ \\
\hline & $\begin{array}{l}\text { Active } \\
\text { microwave }\end{array}$ & $\begin{array}{l}3 \text { days } \\
30 \text { days }\end{array}$ & $\begin{array}{l}3 \mathrm{~km} \\
10 \mathrm{~m}\end{array}$ & $\begin{array}{l}\text { Significant } \\
\text { noise from } \\
\text { vegetation } \\
\text { and } \\
\text { roughness }\end{array}$ & $\begin{array}{c}\text { ERS, JERS, } \\
\text { RadarSat }\end{array}$ \\
\hline $\begin{array}{l}\text { Surface skin } \\
\text { temperature }\end{array}$ & Thermal infrared & $\begin{array}{l}1 \mathrm{~h} \\
1 \text { day } \\
15 \text { days }\end{array}$ & $\begin{array}{l}4 \mathrm{~km} \\
1 \mathrm{~km} \\
60 \mathrm{~m}\end{array}$ & $\begin{array}{l}\text { Soil/vegetation } \\
\text { average, } \\
\text { cloud con- } \\
\text { tamination }\end{array}$ & $\begin{array}{l}\text { GOES, } \\
\text { MODIS, } \\
\text { AVHRR, } \\
\text { Landsat, } \\
\text { ASTER }\end{array}$ \\
\hline Snow cover & $\begin{array}{l}\text { Visible/thermal } \\
\text { infrared }\end{array}$ & $\begin{array}{l}1 \mathrm{~h} \\
1 \text { day } \\
15 \text { days }\end{array}$ & $\begin{array}{l}4 \mathrm{~km} \\
500 \mathrm{~m}-1 \mathrm{~km} \\
30-60 \mathrm{~m}\end{array}$ & $\begin{array}{l}\text { Cloud con- } \\
\text { tamination, } \\
\text { vegetation } \\
\text { masking, } \\
\text { bright soil } \\
\text { problems }\end{array}$ & $\begin{array}{l}\text { GOES, } \\
\text { MODIS, } \\
\text { AVHRR, } \\
\text { Landsat, } \\
\text { ASTER }\end{array}$ \\
\hline \multirow[t]{2}{*}{$\begin{array}{r}\text { Snow water } \\
\text { equivalent }\end{array}$} & $\begin{array}{l}\text { Passive } \\
\text { microwave }\end{array}$ & 1-3 days & $10 \mathrm{~km}$ & $\begin{array}{l}\text { Limited depth } \\
\text { penetration }\end{array}$ & AMSR-E \\
\hline & $\begin{array}{l}\text { Active } \\
\text { microwave }\end{array}$ & 30 days & $100 \mathrm{~m}$ & $\begin{array}{l}\text { Limited } \\
\text { spatial } \\
\text { coverage }\end{array}$ & $\begin{array}{c}\text { SnoSat, SCLP, } \\
\text { Cryosat-2 }\end{array}$ \\
\hline \multirow[t]{2}{*}{$\begin{array}{l}\text { Water } \\
\text { level/velocity }\end{array}$} & Laser & 10 days & $100 \mathrm{~m}$ & $\begin{array}{l}\text { Cloud } \\
\text { penetration } \\
\text { problems }\end{array}$ & $\begin{array}{l}\text { ICESAT, } \\
\text { ICESAT2, } \\
\text { SWOT, } \\
\text { DESDynI }\end{array}$ \\
\hline & Radar & 30 days & $1 \mathrm{~km}$ & $\begin{array}{l}\text { Limited to } \\
\text { large rivers }\end{array}$ & $\begin{array}{l}\text { TOPEX/ } \\
\text { POSEIDON }\end{array}$ \\
\hline $\begin{array}{l}\text { Total water } \\
\text { storage } \\
\text { changes }\end{array}$ & Gravity changes & 30 days & $1,000 \mathrm{~km}$ & $\begin{array}{l}\text { Bulk water } \\
\text { storage } \\
\text { change }\end{array}$ & $\begin{array}{l}\text { GRACE, } \\
\text { GOCS, } \\
\text { GRACEII }\end{array}$ \\
\hline Evaporation & Thermal infrared & $\begin{array}{l}1 \mathrm{~h} \\
1 \text { day } \\
15 \text { days }\end{array}$ & $\begin{array}{l}4 \mathrm{~km} \\
1 \mathrm{~km} \\
60 \mathrm{~m}\end{array}$ & $\begin{array}{l}\text { Significant } \\
\text { assumptions }\end{array}$ & $\begin{array}{l}\text { GOES, } \\
\text { MODIS, } \\
\text { AVHRR, } \\
\text { Landsat, } \\
\text { ASTER }\end{array}$ \\
\hline
\end{tabular}

\section{Background: Land Surface Modelling}

Our knowledge about land surface processes is embedded in land surface models. Models are built upon the analysis of signals entering and leaving the system; they simulate relationships between physical variables in a natural system as a solution of mathematical structures, like simple algebraic equations or more complex systems of partial differential equations (PDEs). Land surface processes are part of the total of global processes controlling the earth, which are typically represented in global general circulation models (GCMs). The land component in these 
models is represented in (largely physically-based) land surface models (LSMs), which simulate the water and energy balance over land. The major state variables of these models include the water content and temperature of soil moisture, snow and vegetation. These variables are referred to as prognostic state variables. Changes in these state variables account for fluxes, e.g., evapotranspiration, which are referred to as diagnostic. Most LSMs are soil-vegetation-atmosphere transfer (SVAT) models, where the vegetation is not a truly dynamic component. Recently, coupling of hydrological or SVAT models with vegetation models has received some attention, to serve more specific ecological, biochemical or agricultural purposes.

Most LSMs used in GCMs view the soil column as the fundamental hydrological unit, ignoring the role of, e.g., topography on spatially variable processes (Stieglitz et al. 1997) to limit the complexity and computations for these coupled models. During the last decades, LSMs were built with a higher degree of complexity in order to better represent land surface atmosphere interactions within GCMs or to meet the need for knowledge of the local state and processes in, for example, environmental or agricultural management studies. This includes, e.g., the treatment of more physiological processes, the improvement of the representation of subgrid heterogeneity and the development of distributed models. Ideally, an improved process representation (system model structure) should result in parameters that are easier to measure or estimate. However, a more complex process representation results in more parameters to be estimated and several authors (Beven 1989; Duan et al. 1992) have stated that LSMs are over-parametrized given the data typically available for calibration.

Land surface models need to be tuned to the specific circumstances under study, mainly to limit systematic prediction errors. Model calibration or parameter estimation relies on observed data and can be defined as a specific type of data assimilation. For large scale land surface modelling, full calibration is nearly impossible. For example, the National Aeronautics and Space Administration (NASA) Land Information System (LIS) allows large scale simulation of land processes with a number of land surface models, which are typically fully parametrized and forced with observation-based datasets. Some examples of widely used LSMs are the Community Land Model (CLM), the Variable Infiltration Capacity Model (VIC), the NOAH Model, the Catchment LSM, and the TOPLATS (TOPMODEL-based Land Atmosphere Transfer Scheme) model.

\section{History of Land Surface Data Assimilation}

In earth sciences, Charney et al. (1969) first suggested combining current and past data in an explicit dynamical model, using the model's prognostic equations to provide time continuity and dynamic coupling amongst the fields. This concept has evolved into a family of techniques known as data assimilation (see chapter Mathematical Concepts of Data Assimilation, Nichols). In essence, land surface 
data assimilation aims to utilize both our hydrological process knowledge as embodied in a land surface model, and information that can be gained from observations. Both model predictions and observations are imperfect and we wish to use both synergistically to obtain a more accurate result. Moreover, both contain different kinds of information, that when used together, provide an accuracy level that cannot be obtained when used individually.

For example, a hydrological model provides both spatial and temporal nearsurface and root zone soil moisture information at the model resolution, including errors resulting from inadequate model physics, parameters and forcing data. On the other hand, remote sensing observations contain near-surface soil moisture information at an instant in time, but do not give the temporal variation or the root zone moisture content. While the remote sensing observations can be used as initialization input for models or as independent evaluation, providing we use a hydrological model that has been adapted to use remote sensing data as input, we can use the hydrological model predictions and remote sensing observations together to keep the simulation on track through data assimilation (Kostov and Jackson 1993). Moreover, large errors in near-surface soil moisture content prediction are unavoidable because of its highly dynamic nature. Thus, when measured soil moisture data are available, their use to constrain the simulated data should improve the overall estimation of the soil moisture profile. However, this expectation is based on the assumption that an update in the upper layer is well propagated to deeper layers. This requires that the model correctly defines the relationship between the upper layer soil moisture and the deeper profile soil moisture (Arya et al. 1983) and that the error correlations between the soil moisture predictions in the upper layer and those in deeper layers are well captured.

Data assimilation techniques were pioneered by meteorologists (Daley 1991) and have been used very successfully to improve operational weather forecasts for decades (see chapter Assimilation of Operational Data, Andersson and Thépaut). Data assimilation has also been widely used in oceanography (Bennett 1992) for improving ocean dynamics prediction (see chapter Ocean Data Assimilation, Haines). However, hydrological data assimilation has just a small number of case studies demonstrating its utility and has very distinct features, when compared to the more chaotic atmospheric or oceanographic assimilation studies. Fortunately, we have been able to develop hydrological data assimilation by building on knowledge derived from the meteorological and oceanographic data assimilation experience, with significant advancements being made over the past decade and an increased interaction between the different earth science branches.

Progress in land surface data assimilation has been primarily limited by a lack of suitable large-domain observations. With the advent of new satellite sensors and technical advances, land surface data assimilation research directions are changing (Margulis et al. 2006). Walker et al. (2003) gave a brief history of hydrological data assimilation, focusing on the use and availability of remote sensing data, and stated that this research field in hydrology is still in its "infancy". Walker and Houser (2005) gave an overview of hydrological data assimilation, discussing 
different data assimilation methods and several case studies in hydrology. van Loon and Troch (2001) gave a review of data assimilation applications in hydrology and added a discussion on the challenges facing future hydrological applications. McLaughlin (1995) reviewed some developments in hydrological data assimilation and McLaughlin (2002) transferred the options of interpolation, smoothing and filtering for state estimation from the engineering sciences to hydrological research.

Soil moisture and soil temperature have been the most studied variables for estimation in land surface models, because of their well-known impact on weather forecasts (Zhang and Frederiksen 2003; Koster et al. 2004) and climate predictions (Dirmeyer 2000). Besides these variables, also snow mass and vegetation properties have received attention. The land surface state variables are highly variable in all three space dimensions. A complete and detailed assessment of these variables is, consequently, a difficult task. Therefore, most studies have focused on data assimilation in one or two dimensions (e.g. soil moisture profiles or single layer fields) and/or relatively simple models.

\subsection{Early Land Surface State Estimation Studies}

The study by Jackson et al. (1981) was among the first to directly update soil moisture predictions using near-surface soil moisture observations. In this application, the soil moisture values in both layers of the United States Department of Agriculture Hydrograph Laboratory model were substituted with observed near-surface soil moisture observations as they became available. The model's performance improvement was evaluated by annual runoff values. Ottlé and VidalMadjar (1994) used a similar approach but with the assimilation of thermal infrared derived near-surface soil moisture content.

Another early study based on the direct insertion assimilation method was that of Bernard et al. (1981). Here, synthetic observations of near-surface soil moisture content were used to specify the surface boundary condition of a classical one-dimensional soil water diffusion model, in order to estimate the surface flux. They found that large soil moisture content variations resulting from rainy periods required special handling of the upper boundary condition. Prevot et al. (1984) repeated this study with real observations and a similar approach was used by Bruckler and Witono (1989). A more popular approach for the improved estimation of land surface fluxes has been the assimilation of screen-level measurements of relative humidity and temperature (Bouttier et al. 1993; Viterbo and Beljaars 1995).

The first known studies to use an "optimal" assimilation approach were those of Milly (1986) and Milly and Kabala (1986). In the first study, a Kalman filter (a statistical assimilation approach) was used to update a simple linear reservoir model with near-surface soil moisture observations. In the second study, an integration of models and remote sensing temperature data using an Extended Kalman filter (EKF) was 
proposed. It was not until Entekhabi et al. (1994) that this approach was extended, when synthetically-derived vertical and horizontal polarized passive microwave and thermal infrared observations were assimilated into a one-dimensional soil moisture and temperature diffusion model using the Kalman filter. This synthetic study was further extended by Walker et al. (2001a, b). Since then, there has been a plethora of one-dimensional Kalman filter and variational assimilation studies.

The use of the Kalman filter for larger scale and multi-dimensional applications was early explored by Georgakakos and Baumer (1996), who used it to update a hydrological basin model with two layers of soil moisture with near-surface basinintegrated soil moisture measurements. Results showed that even when the surface observations carried substantial measurement errors, estimation of soil moisture profiles and total soil moisture storage was possible with an error that was smaller than that achieved without the use of remotely sensed data. Houser et al. (1998) was the first detailed study of several alternative assimilation approaches in a distributed model set-up, including direct insertion, statistical correction, Newtonian nudging and optimal interpolation. Both the Newtonian nudging and optimal interpolation approaches, pathological cases of the Kalman filter, showed the greatest improvement. Walker et al. (2002a) were among the first to use a three-dimensional Kalman filter based assimilation in a small catchment distributed hydrological model, while Reichle and McLaughlin (2001) were at the cutting edge with an advanced four-dimensional "optimal" variational assimilation algorithm, which included a radiative transfer model to directly include remotely sensed brightness temperature.

\subsection{Data Assimilation Beyond State Estimation}

So far in our discussion, data assimilation was meant for state estimation, but we stress that this term can be used for any use or assimilation of observational information for model updating (WMO 1992). Basically, there are four methods for "model updating", depending on what factor is considered to be responsible for the discrepancy between observed and modelled variables:

- Input updating: if model input is erroneous or incorrectly defined, then corrections (e.g. through reanalysis) of the input can improve the model accuracy (improvement of the input forcing);

- State updating: if the model suffers from deficiencies because of a bad state initialization then one could alter the state of the model so that it comes closer to the observations (state estimation, data assimilation in the narrow sense);

- Parameter updating: if the model suffers from deficiencies because of an inefficient parameter choice, one could change the parameters to better adjust the models to the current information (parameter estimation, calibration);

- Error correction: sometimes, the model output should be corrected by an integrated error term in order to approach the observations (e.g. bias correction). 
State updating can be justified by lack of knowledge about the initial conditions for a model, but with unconstrained state updating, the logic of models is foregone, while this is exactly the main strength of dynamic assimilation and modelling. If an intensive update of the state is needed for good results, the model may simply not be able to produce correct state or flux values. In such cases, assimilation for parameter estimation is better advised. The static parameters obtained through off-line calibration, prior to the actual forecast simulations, may not always result in a proper model definition, because of the state and time dependency of parameters or problems in the model structure or input. Often the model validation residuals show the presence of bias, variation in error (heteroscedasticity) and a correlation structure. Several papers reported the use of filtering techniques for parameter estimation (e.g. Katul et al. 1993; Chen and Zhang 2006). Likely, a combined state and parameter estimation (Thiemann et al. 2001) opens most perspectives for good model simulations. Two options can be considered for such an approach: (i) joint estimation of state and parameters, where the state vector is augmented with a parameter vector (Bras and Rodriguez-Iturbe 1985; Evensen 2003), or the objective function for parameter optimization is extended for state estimation (De Lannoy et al. 2006); and (ii) dual estimation, using two interactive filters or optimization procedures (Hebson and Wood 1985; Moradkhani et al. 2005; Gove and Hollinger 2006; Vrugt et al. 2006). The chapter Inverse Modelling and Combined State-Source Estimation for Chemical Weather (Elbern et al.) discusses these ideas in the context of chemical data assimilation.

Another option is to estimate the forecast bias, as an integrated value for all errors in the parameters, the forcings and the model structure along with the state estimation, as originally presented by Friedland (1969) and Dee and da Silva (1998). Among the first studies on forecast bias estimation in land surface models were Bosilovich et al. (2007) for skin temperature assimilation and De Lannoy et al. (2007a, b) for soil moisture data assimilation.

In the remainder of this chapter, we mainly limit data assimilation to state estimation.

\section{General Concept of Land Surface Data Assimilation}

The data assimilation challenge is: given a (noisy) model of the system dynamics, find the best estimates of system states $\hat{\mathbf{x}}$ from (noisy) observations $\mathbf{y}$. Most current approaches to this problem are derived from either the direct observer (i.e., sequential filter) or dynamic observer (i.e., variational through time) techniques. Figure 2 illustrates schematically the key differences between these two approaches to data assimilation. To help the reader through the large amount of jargon typically associated with data assimilation, a list of terminology has been provided (Table 2). We adopt the convention of lowercase bold symbols for vectors and uppercase bold symbols for matrices. Non-linear operators are in bold Kunstler script; their linearization is represented as for a matrix. This section complements material in the chapters in Part I, Theory. 

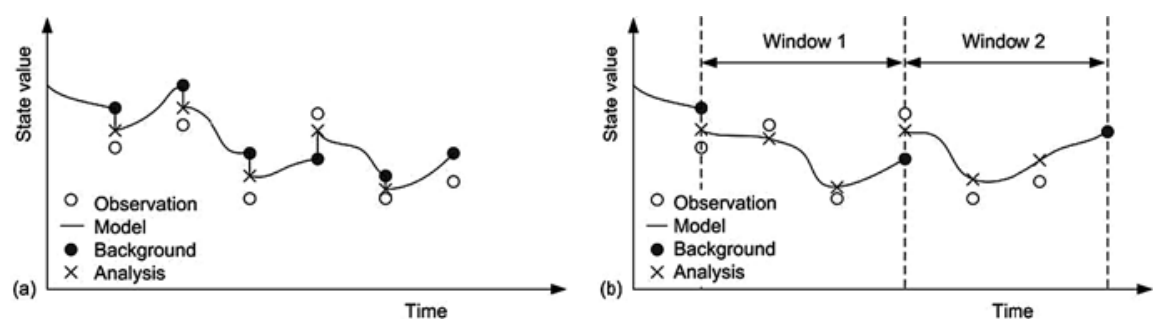

Fig. 2 Schematic of the (a) direct observer and (b) dynamic observer assimilation approaches

Table 2 Commonly used data assimilation terminology

\begin{tabular}{|c|c|}
\hline State & Condition of a physical system, e.g. soil moisture \\
\hline State error & Deviation of the estimated state from the truth \\
\hline Prognostic & A model state required to propagate the model forward in time \\
\hline Diagnostic & $\begin{array}{l}\text { A model state/flux diagnosed from the prognostic states - not } \\
\text { required to propagate the model }\end{array}$ \\
\hline Observation & Measurement of a model diagnostic or prognostic \\
\hline Covariance matrix & $\begin{array}{l}\text { Describes the uncertainty in terms of standard deviations and } \\
\text { correlations }\end{array}$ \\
\hline Prediction & Model estimate of states \\
\hline Update & Correction to a model prediction using observations \\
\hline Background & Forecast, prediction or state estimate prior to an update \\
\hline Analysis & State estimate after an update \\
\hline Innovation & Observation-minus-prediction, a priori residual \\
\hline Gain matrix & Correction factor applied to the innovation \\
\hline Tangent linear model & $\begin{array}{l}\text { Linearized (using Taylor's series expansion) version of a non-linear } \\
\text { model }\end{array}$ \\
\hline Adjoint & Operator allowing the model to be run backwards in time \\
\hline
\end{tabular}

\subsection{Direct Observer Assimilation}

The direct observer techniques sequentially update the model forecast $\hat{\mathbf{x}}_{k}^{b}$ (a priori simulation result), using the difference between observation $\mathbf{y}_{k}$ and model predicted observation $\hat{\mathbf{y}}_{k}$, known as the "innovation", whenever observations are available. The predicted observation is calculated from the model predicted or "background" states, indicated by the superscript $b$. The correction, or analysis increment, added to the background state vector is the innovation multiplied by a weighting factor or gain $\mathbf{K}$. The resulting estimate of the state vector is known as the "analysis", as indicated by the superscript $a$.

$$
\hat{\mathbf{x}}_{k}^{a}=\hat{\mathbf{x}}_{k}^{b}+\mathbf{K}_{k}\left(\mathbf{y}_{k}-\hat{\mathbf{y}}_{k}\right)
$$

The subscript $k$ refers to the time of the update. For particular assimilation techniques, like the Kalman filter, the gain represents the relative uncertainty in the 
observation and model variances, and is a number between 0 and 1 in the scalar case. If the uncertainty of the predicted observation (as calculated from the background states and their uncertainty) is large relative to the uncertainty of the actual observation, then the analysis state vector takes on values that will closely yield the actual observation. Conversely, if the uncertainty of the predicted observation is small relative to the uncertainty of the actual observation, then the analysis state vector is unchanged from the original background value. The commonly used direct observer methods are: (i) direct insertion; (ii) statistical sorrection; (iii) successive correction; (iv) analysis correction; (v) nudging; (vi) optimal interpolation/statistical interpolation; (vii) 3-D variational, 3D-Var; and (viii) Kalman filter and variants.

While approaches like direct insertion, nudging and optimal interpolation are computationally efficient and easy to implement, the updates do not account for observation uncertainty or utilize system dynamics in estimating model background state uncertainty, and information on estimation uncertainty is limited. The Kalman filter, while computationally demanding in its pure form, can be adapted for nearreal-time application and provides information on estimation uncertainty. However, it has only limited capability to deal with different types of model errors, and necessary linearization approximations can lead to unstable solutions. The Ensemble Kalman filter (EnKF), while it can be computationally demanding (depending on the size of the ensemble) is well suited for near-real-time applications without any need for linearization, is robust, very flexible and easy to use, and is able to accommodate a wide range of model error descriptions.

\subsection{Dynamic Observer Assimilation}

The dynamic observer techniques find the best fit between the forecast model state and the observations, subject to the initial state vector uncertainty $\mathbf{P}_{0}^{b}$ and observation uncertainty $\mathbf{R}$, by minimizing over space and time an objective or penalty function $J$, including a background and observation penalty term, such as

$$
J\left(\mathbf{x}_{0}\right)=1 / 2\left(\mathbf{x}_{0}-\hat{\mathbf{x}}_{0}^{b}\right)^{T} \mathbf{P}_{0}^{b^{-1}}\left(\mathbf{x}_{0}-\hat{\mathbf{x}}_{0}^{b}\right)+1 / 2 \sum_{k=0}^{N-1}\left(\mathbf{y}_{k}-\mathbf{y}_{k}^{0}\right)^{T} \mathbf{R}_{k}^{-1}\left(\mathbf{y}_{k}-\mathbf{y}_{k}^{0}\right)
$$

where the superscript $b$ refers to the initial or "background" estimate of the state vector, the subscript $k$ refers to time, $N$ is the number of time steps, and $T$ denotes the transpose. The term $\mathbf{y}_{k}^{0}$ in the observation penalty is based on the result of propagating the state guess $\mathbf{x}_{0}$ to future time steps: for a particular estimated state realization $\hat{\mathbf{x}}_{0}^{a}, \mathbf{y}_{k}^{0}$ becomes $\hat{\mathbf{y}}_{k}$. To minimize the objective function over time, an assimilation time "window" is defined and an "adjoint" model is typically used to find the derivatives of the objective function with respect to the initial model state vector $\mathbf{x}_{0}$. The adjoint is a mathematical operator that allows one to determine the sensitivity of the objective function to changes in the solution of the state equations by a single forward and backward pass over the assimilation window. While 
an adjoint is not strictly required (i.e., a number of forward passes can be used to numerically approximate the objective function derivatives with respect to each state), it makes the problem computationally tractable. The dynamic observer techniques can be considered simply as an optimization or calibration problem, where the state vector - not the model parameters - at the beginning of each assimilation window is "calibrated" to the observations over that time period.

The dynamic observer techniques can be formulated with: (i) strong constraint (variational); (ii) weak constraint (dual variational or representer methods). Strong constraint is where the model is assumed perfect, as in Eq. (2), while weak constraint is where errors in the model formulation are taken into account as process noise. This is achieved by including an additional term in Eq. (2) so that

$$
\begin{aligned}
J\left(\mathbf{x}_{0}\right)= & 1 / 2\left(\mathbf{x}_{0}-\hat{\mathbf{x}}_{0}^{b}\right)^{T} \mathbf{P}_{0}^{b^{-1}}\left(\mathbf{x}_{0}-\hat{\mathbf{x}}_{0}^{b}\right) \\
& +1 / 2 \sum_{k=0}^{N-1}\left(\mathbf{y}_{k}-\mathbf{y}_{k}^{0}\right)^{T} \mathbf{R}_{k}^{-1}\left(\mathbf{y}_{k}-\mathbf{y}_{k}^{0}\right)+1 / 2 \sum_{k=0}^{N-1} \boldsymbol{\eta}_{k}^{T} \mathbf{Q}_{k}^{-1} \boldsymbol{\eta}_{k},
\end{aligned}
$$

where $\boldsymbol{\eta}$ is the model error vector and $\mathbf{Q}$ is the model error covariance matrix.

Dynamic observer methods are well suited for smoothing problems, but provide information on estimation accuracy only at considerable computational cost. Moreover, adjoints are not available for many existing hydrological models, and the development of robust adjoint models is difficult due to the non-linear nature of hydrological processes.

\subsection{Features of Data Assimilation}

The potential benefit of data assimilation for hydrological science is tremendous and can be summarized as follows (adapted from Rood et al. 1994). Data assimilation:

- Organizes the data by objectively interpolating information from the observation space to the model space. The raw observations are organized and given dynamical consistency with the model equations, thereby enhancing their usefulness;

- Supplements the data by constraining the model's physical equations with parsimonious observations, which can be used to estimate unobserved quantities. This allows the progress of research that would be impossible without assimilation, because it allows for a more complete understanding of the true state of a hydrological system (see Fig. 3a);

- Complements the data by propagating information into regions of sparse observations using either observed spatial and temporal correlations, or the physical relationships included in the model (see Fig. 3b);

- Quality controls the data through comparison of observations with previous forecasts to identify and eliminate spurious data. By performing this comparison 
a)
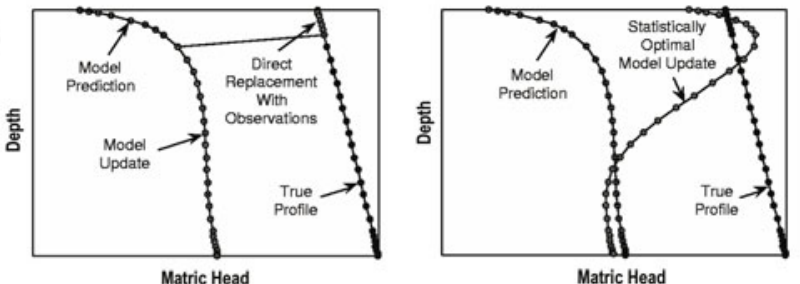

b)

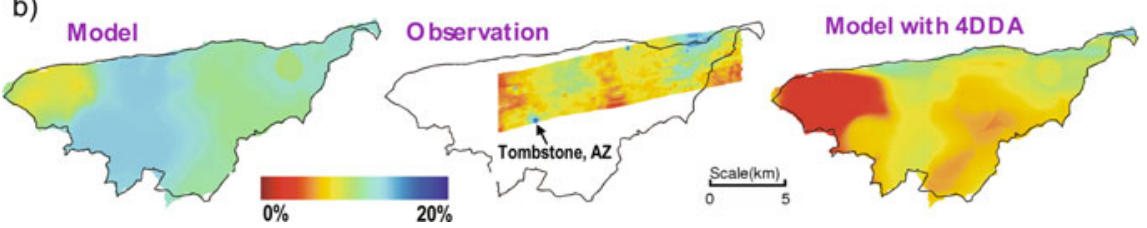

Fig. 3 Example of how data assimilation supplements data and complements observations: (a) Numerical experiment results demonstrating how near-surface soil moisture measurements are used to retrieve the unobserved root zone soil moisture state using (left panel) direct insertion and (right panel) a statistical assimilation approach (Walker et al. 2001a); (b) Six Push Broom Microwave Radiometer (PBMR) images gathered over the USDA-ARS Walnut Gulch Experimental Watershed in Arizona were assimilated into the TOPLATS hydrological model using several alternative assimilation procedures (Houser et al. 1998). The observations were found to contain horizontal correlations with length scales of several tens of $\mathrm{km}$, thus allowing soil moisture information to be advected beyond the area of the observations

repeatedly, it is possible to calibrate observing systems and identify biases or changes in observation system performance;

- Validates and improves the hydrological models by continuous model confrontation with real data. This helps to identify model weaknesses, such as systematic errors, and correct them.

\subsection{Quality Control for Data Assimilation}

One of the major components of any data assimilation system is quality control of the input data stream. Quality control is a pre-assimilation rejection or correction of questionable or bad observations, which begins where the remote sensing product quality control activities end. The observational data from remote sensing systems contain errors that can be classified into two types:

- Natural error (including instrument and representativeness error);

- Gross error (including improperly calibrated instruments, incorrect registration or coding of observations, and telecommunication error).

These errors can be either random or spatially and/or temporally correlated with each other; inversion techniques and instrument biases can be correlated in time and 
space, and calibrations of remote sensing instruments can drift. To address these problems a number of quality control operations are performed.

The quality control process consists of a set of algorithms which examine each data item, individually or jointly, in the context of additional information. Their primary purpose is to determine which of the data are likely to contain unknown (incorrigible) gross errors, and which are not. Quality control proceeds in a three step process: (i) test for potential problem observations; (ii) attempt to correct the problem observation; and (iii) decide the fate of the observation (data rejection). The quality control algorithms can be categorized as follows:

- Quality control flags are used to check the data for inconsistencies noted during the measurement, transmission, pre/post processing and archiving stages;

- Consistency or sanity checks see if the observation absolute value or time rate of change is physically realistic. This check filters such things as observations outside the expected range, unit conversion problems, etc.;

- Buddy checks compare the observation with comparable nearby (space and time) observations of the same type and reject the questioned observation if it exceeds a predefined level of difference;

- Background checks examine if the observation is changing similarly to the model prediction. If it is not, and the user has some reasonable confidence in the model, the observation may be questioned.

\subsection{Validation Using Data Assimilation}

The continuous confrontation of model predictions with observations in a data assimilation system presents a rich opportunity to better understand physical processes and observational quality in a structured, iterative, and open-ended learning process. Inconsistencies between observations and predictions are easily identified in a data assimilation system, providing a basis for observational quality control and validation. Systematic differences between observations and model predictions can identify systematic errors. This methodology clearly illustrates the importance of a good quality forecast and an analysis that is reasonably faithful to the observations. If the hydrological model makes reasonably good predictions, then the analysis must only make small changes to an accurate background field.

The validation of observations in a data assimilation system is centred on: (i) comparisons of new observations with the model forecast and the data assimilation analysis; and (ii) interpretation of the forecast error covariances. The data assimilation validation algorithms can be categorized as follows:

- Innovation evaluation compares the observation with the model prediction as either a single point in time or change over time; large or obvious deviations from the model prediction are likely wrong. Means, standard deviations, and time evolution of observed minus predicted fields are examined with the goal of detecting abrupt changes. This allows the estimation of forecast and/or observation bias; 
- Analysis residual evaluation compares the observation with the data assimilation analysis. Examination of the means, standard deviations, and time evolution of observed minus predicted fields will help to diagnose systematic or abrupt observation system changes. This technique is useful to diagnose the performance of the analysis, and test if the observations are being used effectively (Hollingsworth and Lönnberg 1989). Filter optimization can be achieved through adaptive filtering, using residual information;

- Observation withholding is a stringent method for validation in an assimilation system where some of the observational data are withheld from the analysis procedure in data-dense regions. This allows the analysis to be validated against the withheld observations;

- Error propagation is undertaken and changes in the regional distribution or absolute value of these errors could indicate observational problems;

- Model and observation bias is generally assumed to be zero and uncorrelated in space. These assumptions work reasonably well for in situ observations, but satellite observations are usually biased by inaccurate algorithms, and their errors are usually horizontally correlated because the same sensor is making all the observations. With recent work by Dee and Todling (2000) the bias of the model and observations can be continuously estimated and corrected for. Evaluation of these bias estimates in space and time may lead to additional insights on the observational characteristics.

\section{Land Surface Data Assimilation Techniques}

The text in Sect. 6 complements that in several chapters in Part I, Theory.

\subsection{Land Surface System}

Land surface hydrology process models are typically non-linear, and can be considered to forecast the system state vector $\mathbf{x}$ at time $k+1$ as a function of the system state vector estimate at the previous time step $k$ and a forcing vector $\mathbf{u}$. The model state forecast is subject to a model error vector $\eta$, which represents errors in the model forcing data, initial conditions, parameters and physics. As a result the state is a random variable and cannot be calculated as a classical solution of the deterministic system equations. The state propagation equation is given by

$$
\mathbf{x}_{k+1}=\mathcal{M}_{k}\left(\mathbf{x}_{k}, \mathbf{u}_{k}\right)+\eta_{k}
$$

Where $\mathcal{M}$ is a non-linear operator and $\eta$ is assumed additive for simplicity. This equation can be linearized to obtain the "tangent linear model" as

$$
\mathbf{x}_{k+1}=\mathbf{M}_{k} \mathbf{x}_{k}+\mathbf{B}_{k} \mathbf{u}_{k}+\eta_{k}
$$


with $\mathbf{M}$ and $\mathbf{B}$ the linear state transition matrix and the linear matrix relating the input to the state. The state space equation is subject to the initial state vector

$$
\hat{\mathbf{x}}_{0}=\mathbf{x}_{0}+\boldsymbol{\delta}_{0}
$$

which is an approximation of the truth $\mathbf{x}$ and an error vector $\delta$ at time step $k=0$. All subsequent forecasts $\hat{\mathbf{x}}_{k+1}^{b}$ (predictions, background information for data assimilation) are estimated through the model propagation by:

$$
\hat{\mathbf{x}}_{k+1}^{b}=\mathcal{M}_{k}\left(\hat{\mathbf{x}}_{k}^{a}, \mathbf{u}_{k}\right),
$$

with $\hat{\mathbf{x}}_{k}^{a}$ the analysis state obtained through data assimilation at the previous time step, or, if the analysis is unavailable, then $\hat{\mathbf{x}}_{k}^{a}$ is replaced by the best a priori estimate (prediction) $\hat{\mathbf{x}}_{k}^{b}$ at the previous time step.

Often the state variables are not measured directly, but some other related output from the system is observed. The observation equation is given by

$$
\mathbf{y}_{k}=\mathcal{H}_{k}\left(\mathbf{x}_{k}\right)+\boldsymbol{\varepsilon}_{k}
$$

where $\mathcal{H}$ is a non-linear operator which relates the system state to the output observation, $\mathbf{y}$ is the actual observation and $\boldsymbol{\varepsilon}$ is an error vector (assumed additive for simplicity). This equation can also be linearized as

$$
\mathbf{y}_{k}=\mathbf{H}_{k} \mathbf{x}_{k}+\boldsymbol{\varepsilon}_{k}
$$

The observation predictions $\hat{\mathbf{y}}_{k}$ are a transformation of the model forecasts to the observation space:

$$
\hat{\mathbf{y}}_{k}=\mathcal{H}_{k}\left(\hat{\mathbf{x}}_{k}^{b}\right)
$$

A typical observation system in hydrological applications is the transformation $\mathcal{H}_{k}$ of land surface model state variables ( $\hat{\mathbf{x}}_{k}^{b}$, e.g., soil moisture) to the actual values measured by satellites $\left(\hat{\mathbf{y}}_{k}\right.$, e.g., brightness temperature), based on radiative transfer theory.

Data assimilation aims at using the difference between the observation predictions $\hat{\mathbf{y}}_{k}$ and the actual observations $\mathbf{y}_{k}$ to update the model state. Several assimilation techniques explicitly take into account information on the error characterization. The key assumptions of the linear optimal assimilation approaches that will be discussed in this chapter, are that the error terms $\boldsymbol{\eta}, \boldsymbol{\delta}_{0}$ and $\boldsymbol{\varepsilon}$ are uncorrelated (white) through time and have zero mean Gaussian distributions as represented by their covariance matrices $\mathbf{Q}, \mathbf{P}_{0}{ }^{b}$ and $\mathbf{R}$, respectively. That is

$$
\begin{array}{ll}
\mathcal{E}\left(\boldsymbol{\eta}_{k}\right)=0 & \mathcal{E}\left(\boldsymbol{\eta}_{k} \boldsymbol{\eta}_{k}^{T}\right)=\mathbf{Q}_{k} \\
\mathcal{E}\left(\boldsymbol{\delta}_{0}\right)=0 & \mathcal{E}\left(\boldsymbol{\delta}_{0} \boldsymbol{\delta}_{0}^{T}\right)=\mathbf{P}_{0}^{b} \\
\mathcal{E}\left(\boldsymbol{\varepsilon}_{k}\right)=0 & \mathcal{E}\left(\boldsymbol{\varepsilon}_{k} \boldsymbol{\varepsilon}_{k}^{T}\right)=\mathbf{R}_{k}
\end{array}
$$


where $\mathcal{E}($.$) is the expectation operator. The assumption that observational and model$ errors are unbiased relative to each other and the "truth" is the most restrictive assumption, the most commonly violated assumption, and the most detrimental assumption in terms of predictive performance.

\subsection{Direct Observer Data Assimilation}

One key question in the direct observer data assimilation technique, and the fundamental difference between the various methods, is the choice of the gain matrix $\mathbf{K}$ in equation

$$
\hat{\mathbf{x}}_{k}^{a}=\hat{\mathbf{x}}_{k}^{b}+\mathbf{K}_{k}\left(\mathbf{y}_{k}-\hat{\mathbf{y}}_{k}\right)
$$

Ultimately $\mathbf{K}_{k}$ should be chosen such that $\hat{\mathbf{x}}_{k}^{a}$ approaches the expectation of $\mathbf{x}_{k}$, as $k$ approaches infinity (as an approximation of the theoretical ensemble mean of the stochastic process). Under the assumption of perfect knowledge of the error characteristics and for linear systems, this can be achieved by choosing $\mathbf{K}$ as the optimal least squares estimator or Best Linear Unbiased Estimate (BLUE) analysis as used for the Kalman gain in the linear Kalman filter (see below). The optimal gain can be shown analytically to be (Jazwinski 1970; Maybeck 1979)

$$
\mathbf{K}_{k}=\mathbf{P}_{k}^{b} \mathbf{H}_{k}^{T}\left(\mathbf{H}_{k} \mathbf{P}_{k}^{b} \mathbf{H}_{k}^{T}+\mathbf{R}_{k}\right)^{-1},
$$

where $\mathbf{H}_{k} \mathbf{P}_{k}^{b} \mathbf{H}_{k}^{T}=\hat{\mathbf{R}}_{k}$ is the error covariance matrix of the predicted observation $\hat{\mathbf{y}}_{k}$. However, approximations to the optimal filter equations and/or alternative methodologies of solving the key equations have been sought to limit some difficulties in the practical numerical approximation of this optimal solution.

Direct insertion: One of the earliest and most simplistic approaches to data assimilation is direct insertion. As the name suggests, the forecast model states are directly replaced with the observations by assuming that $\mathbf{K}=\mathbf{I}$, the unity matrix. This approach makes the explicit assumption that the model is wrong (has no useful information) and that the observations are right, which both disregards important information provided by the model and preserves observational errors. The risk of this approach is that unbalanced state estimates may result, which causes model shocks: the model will attempt to restore the dynamic balance that would have existed without insertion. A further key disadvantage of this approach is that model physics are solely relied upon to propagate the information to unobserved parts of the system (Houser et al. 1998; Walker et al. 2001a).

Statistical correction: A derivative of the direct insertion approach is the statistical correction approach, which adjusts the mean and variance of the model states to match those of the observations. This approach assumes the model pattern is correct but contains a non-uniform bias. First, the predicted observations are scaled by 
the ratio of observational field standard deviation to predicted field standard deviation. Second, the scaled predicted observational field is given a block shift by the difference between the means of the predicted observational field and the observational field (Houser et al. 1998). This approach also relies upon the model physics to propagate the information to unobserved parts of the system.

Successive correction: The successive corrections method (SCM) was developed by Bergthorsson and Döös (1955) and Cressman (1959), and is also known as observation nudging. The scheme begins with an a priori state estimate (background field) for an individual (scalar) variable $\hat{x}_{k}^{b} \in \hat{\mathbf{x}}_{k}^{b}$, which is successively adjusted by nearby observations in a series of scans (iterations, $n$ ) through the data. The analysis at time step $k$ is found by passing through the following sequence of updates:

$$
\left\{\begin{aligned}
\hat{x}_{k}^{a, 0} & =\hat{x}_{k}^{b} \\
\hat{x}_{k}^{a, 1} & =\hat{x}_{k}^{a, 0}+\mathbf{k}_{k}^{1^{T}}\left(\mathbf{y}_{i}-\mathcal{H}_{k}\left(\hat{\mathbf{x}}_{k}^{a, 0}\right)\right) \\
& \vdots \\
\hat{x}_{k}^{a, n} & =\hat{x}_{k}^{a, n-1}+\mathbf{k}_{k}^{n^{T}}\left(\mathbf{y}_{i}-\mathcal{H}_{k}\left(\hat{\mathbf{x}}_{k}^{a, n-1}\right)\right)
\end{aligned}\right.
$$

with $\mathcal{H}_{k}\left(\hat{\mathbf{x}}_{k}^{a, n}\right)$ the value of the state estimate at the $n$th iteration, evaluated at all observation points $\left(\mathcal{H}_{k}\right.$ is the non-linear interpolation operator), $\mathbf{y}_{i}$ the vector of all observations within a predefined influence radius $R_{k}^{n}$ and $\mathbf{k}_{k}^{n}$ is a vector of weights for all observations within the predefined radius of influence. The elements $k_{j, k}^{n} \in \mathbf{k}_{k}^{n}$ $(j=1, \ldots, m$ for all observations) are given by:

$$
k_{j, k}^{n}=\frac{c_{j, k}^{n}}{q^{2}+\sum_{j=1}^{m} c_{j, k}^{n}}
$$

with $q$ an estimate of the ratio of the observation error to the background error covariance, $c_{j, k}^{n}$ any sort of weights. Different weighting functions could be proposed, but for the Cressman scheme, the observations are assumed to be perfect $\left(q^{2}=0\right)$ and the weights are given by:

$$
c_{j, k}^{n}=\left\{\begin{array}{cc}
\frac{R_{k}^{n^{2}}-d_{j}^{2}}{R_{k}^{n^{2}}+d_{j}^{2}} & d_{j}<R_{k}^{n} \\
0 & d_{j} \geq R_{k}^{n}
\end{array}\right.
$$

with $R_{k}^{n}$ the radius of influence, which is mostly shrinking for successive iterations $n$, so that the field is corrected to larger scale features during the first iterations, and conforms to smaller scale features during later iterations; $d_{j}$ is the distance between the $j$ th observation point and the grid point for the analysis.

For the estimation of the complete state vector $\hat{\mathbf{x}}_{k}^{a}$ (i.e., multiple grid points), the equation would be as follows for each iteration $n$ : 


$$
\hat{\mathbf{x}}_{k}^{a, n}=\hat{\mathbf{x}}_{k}^{a, n-1}+\mathbf{K}_{k}^{n-1}\left(\mathbf{y}_{k}-\hat{\mathbf{y}}_{k}\right)=\hat{\mathbf{x}}_{k}^{a . n-1}+\mathbf{K}_{k}^{n-1}\left(\mathbf{y}_{k}-\mathcal{H}_{k}\left(\hat{\mathbf{x}}_{k}^{a, n-1}\right)\right)
$$

with $\mathbf{K}$ a matrix containing an empirically derived weighting, that takes into account the spatial distribution of observations.

The advantage of this method lies in its simplicity. However, in case of observational error or different sources (and accuracies) of observations, this scheme is not a good option for assimilation, since information on the observational accuracy is not accounted for. Mostly, this approach assumes that the observations are more accurate than model forecasts, with the observations fitted as closely as is consistent. Furthermore, the radii of influence are user-defined and should be determined by trial and error or more sophisticated methods that reduce the advantage of its simplicity. The weighting functions are empirically chosen and are not derived based on physical or statistical properties. Obviously, this method is not effective in data sparse regions. Some practical examples are discussed by Bratseth (1986) and Daley (1991).

Analysis correction: This is a modification to the successive correction approach that is applied consecutively to each observation $s$ from 1 to $s_{f}$ as in Lorenc et al. (1991). In practice, the observation update is mostly neglected and further assumptions make the update equation equivalent to that for optimal interpolation (Nichols 2001).

Nudging: Nudging or Newtonian relaxation consists of adding a term to the prognostic model equations that causes the solution to be gradually relaxed towards the observations. Nudging is very similar to the successive corrections technique and only differs in the fact that through the numerical model the time dimension is included. Two distinct approaches have been developed (Stauffer and Seaman 1990). In analysis nudging, the nudging term for a given variable is proportional to the difference between the model simulation at a given grid point and an "analysis" of observations (i.e., processed observations) calculated at the corresponding grid point. For observation nudging, the difference between the model simulation and the observed state is calculated at the observation locations.

The nudging approach approximates the gain matrix by the empirical function

$$
\mathbf{K} \approx G\left(\mathbf{W}^{T} \mathbf{\Theta}\right)(\mathbf{W I})^{-1}
$$

where $G$ is a nudging factor that gives the magnitude of the nudging term and has a value from 0 to $1, \Theta$ is an observational quality factor with a value from 0 to 1 , $\mathbf{I}$ is the identity matrix and $\mathbf{W}$ is a temporal and spatial weighting function, also with a value from 0 to 1 . The function $\mathbf{W}$ is given by $w_{x y} w_{z} w_{t}$, where $w_{x y}$ is a horizontal weighting function (i.e., Cressman), $w_{z}$ is a similar vertical weighting function, and $w_{t}$ is a temporal weighting function. Each of these temporal/spatial weighting functions has a value from 0 to 1 .

Optimal interpolation: The optimal interpolation (OI) approach, sometimes referred to as statistical interpolation, approximates the "optimal" solution from Eq. (12) by choosing 


$$
\mathbf{K}_{k}=\mathbf{P}^{\prime b} \mathbf{H}_{k}^{T}\left(\mathbf{H}_{k} \mathbf{P}^{\prime b} \mathbf{H}_{k}^{T}+\mathbf{R}_{k}\right)^{-1}
$$

where $\mathbf{P}^{\prime b}$ is an approximated background covariance matrix, often with a "fixed" structure for all time steps, given by prescribed variances and a correlation function determined only by distance (Lorenc 1981). Sometimes, the variances are allowed to evolve in time, while keeping the correlation structure time-invariant.

3-D Var: 3D-variational assimilation directly solves the iterative minimization problem given by Eqs. (2) or (3) for $N=1$ (Parrish and Derber 1992). The same approximation for the background covariance matrix as in the optimal interpolation approach is typically used.

Kalman filter: The optimal analysis state estimate $\hat{\mathbf{x}}_{k}^{a}$ for linear or linearized systems (Kalman or Extended Kalman filter, EKF) can be found through a linear update equation with a Kalman gain that aims at minimizing the analysis error (co)variance of the analysis state estimate (Kalman 1960). As indicated earlier, the optimal gain can be shown analytically to be

$$
\mathbf{K}_{k}=\mathbf{P}_{k}^{b} \mathbf{H}_{k}^{T}\left(\mathbf{H}_{k} \mathbf{P}_{k}^{b} \mathbf{H}_{k}^{T}+\mathbf{R}_{k}\right)^{-1}
$$

The updated (analysis) state uncertainty (analysis error covariance) is given by:

$$
\mathbf{P}_{k}^{a}=\left(\mathbf{I}-\mathbf{K}_{k} \mathbf{H}_{k}\right) \mathbf{P}^{b}\left(\mathbf{I}-\mathbf{K}_{k} \mathbf{H}_{k}\right)^{T}+\mathbf{K}_{k} \mathbf{R}_{k} \mathbf{K}_{k}^{T},
$$

which reduces to

$$
\mathbf{P}_{k}^{a}=\left(\mathbf{I}-\mathbf{K}_{k} \mathbf{H}_{k}\right) \mathbf{P}_{k}^{b},
$$

if, and only if, the optimal Kalman gain is used.

The essential feature which distinguishes the family of Kalman filter approaches from more static techniques, like optimal interpolation, is the dynamic updating of the forecast (background) error covariance through time. In the traditional Kalman filter (KF) approach this is achieved by application of standard error propagation theory, using the (tangent) linear model in Eq. (5). (The only difference between the Kalman filter and the Extended Kalman filter is that the forecast model is linearized using a Taylor series expansion in the latter; the same forecast and update equations are used for each approach.). The state covariance forecast equation is

$$
\mathbf{P}_{k+1}^{b}=\mathbf{M}_{k} \mathbf{P}_{k}^{b} \mathbf{M}_{k}^{T}+\mathbf{Q}_{k}
$$

where $\mathbf{M}_{k}$ is the linear operator from Eq. (5) and $\mathbf{Q}$ is the model error covariance matrix given in Eq. (11). Thus, the (Extended) Kalman filter requires propagation of the state covariances along with the states, which might be computationally expensive and approximative, because of the system linearization. While the approach gives an optimal analysis for the assumed statistics - see Eq. (11), the initial state 
error covariance matrix $\mathbf{P}_{0}$ and, more seriously, the model error covariance matrix $\mathbf{Q}$ are difficult to define, and often assumed ad hoc.

Equations (1), (7), (10), (12), and (21) form the basis of the Kalman filter approach (Kalman 1960) to data assimilation. On the assimilation time interval $k \in[0, N]$, the analysis $\hat{\mathbf{x}}_{k}^{a}$ given by the Kalman filter should be equal to the converged solution obtained by the variational adjoint method at time $k=N$.

The standard Extended Kalman filter update and state covariance forecast equations can be applied directly with a non-linear state forecast model after linearization. This is achieved by numerically approximating the Jacobians $\mathbf{M}$ and $\mathbf{H}$ at each time step $k$ as required by

$$
\begin{gathered}
\mathbf{M}_{k}=\left[\begin{array}{ccc}
\frac{\partial \mathcal{M}_{1}}{\partial x_{1}} & \cdots & \frac{\partial \mathcal{M}_{1}}{\partial x_{n}} \\
\vdots & \ddots & \vdots \\
\frac{\partial \mathcal{M}_{n}}{\partial x_{1}} & \cdots & \frac{\partial \mathcal{M}_{n}}{\partial x_{n}}
\end{array}\right]_{\left(\hat{\mathbf{x}}_{k}^{b}, \mathbf{u}_{k}, \mathbf{w}_{k}=\mathbf{0}\right)} \approx \frac{\partial \hat{\mathbf{x}}_{k+1}^{b}}{\partial \hat{\mathbf{x}}_{k}^{b}} \text { and } \\
\mathbf{H}_{k}=\left[\begin{array}{ccc}
\frac{\partial \mathcal{H}_{1}}{\partial x_{1}} \cdots & \frac{\partial \mathcal{H}_{1}}{\partial x_{n}} \\
\vdots & \ddots & \vdots \\
\frac{\partial \mathcal{H}_{n}}{\partial x_{1}} & \cdots & \frac{\partial \mathcal{H}_{n}}{\partial x_{n}}
\end{array}\right]_{\left(\hat{\mathbf{x}}_{k}^{b}, \mathbf{v}_{k}=\mathbf{0}\right)} \approx \frac{\partial \hat{\mathbf{y}}_{k}}{\partial \hat{\mathbf{x}}_{k}^{b}}
\end{gathered}
$$

However, the cost of doing this is $n+1$ times the standard model run time, where $n$ is the number of state variables to be updated by the assimilation. Note that only states with significant correlation to the observation need be included in the state covariance forecast and update (Walker and Houser 2001). Walker et al. (2001b) avoided the Taylor expansion linearization by adopting a Crank-Nicholson scheme to represent the state propagation.

A further approach to estimating the state covariance matrix is the Ensemble Kalman filter (EnKF). As the name suggests, the covariances are calculated from an ensemble of state forecasts using the Monte Carlo approach rather than a single discrete forecast of covariances. In this case, $N$ ensemble members of model predicted states $\hat{\mathbf{x}}_{k}^{b}$ (each containing $n$ state variables) are stored as $\hat{\mathbf{X}}_{k}^{b}$ using different initial conditions and forcing (Turner et al. 2007), different parameters and/or models, different model error (e.g. additive/multiplicative), etc., in order to get a representative spread of state forecasts amongst the ensemble members. While this is quite straightforward, the question of what model error $\eta$ to apply, and how, is still a major unknown. Moreover, special care is required when the number of ensembles $N$ is less than the number of observations $m$.

Using this approach, the background state covariance matrix is calculated as

$$
\mathbf{P}_{k}^{b}=\frac{\left(\hat{\mathbf{X}}_{k}^{b}-\overline{\hat{\mathbf{X}}}_{k}^{b}\right)\left(\hat{\mathbf{X}}_{k}^{b}-\overline{\hat{\mathbf{X}}}_{k}^{b}\right)^{T}}{N-1} .
$$


where $\overline{\hat{\mathbf{X}}}_{k}^{b}$ is a matrix with all identical columns of ensemble mean state estimates. This could then be used in Eq. (12) directly, except some mathematical techniques are typically used so only matrices of size $(n \times m)$ are required (Evensen 1994; Houtekamer and Mitchell 1998). Thus, $\mathbf{P}^{b}$ is never calculated explicitly. Here the analysis equation for each member $j$ is presented as

$$
\hat{\mathbf{x}}_{j, k}^{a}=\hat{\mathbf{x}}_{j, k}^{b}+\mathbf{B}_{k}^{T} \mathbf{b}_{j, k}
$$

where

$$
\begin{gathered}
\mathbf{B}_{k}^{T}=\mathbf{P}_{k}^{b} \mathbf{H}_{k}^{T} \\
\mathbf{b}_{j, k}=\left(\mathbf{H}_{k} \mathbf{P}_{k}^{b} \mathbf{H}_{k}^{T}+\mathbf{R}_{k}\right)^{-1}\left(\mathbf{y}_{k}-\hat{\mathbf{y}}_{j, k}\right) .
\end{gathered}
$$

By rearranging Eq. (27a) and introducing a zero mean random observation error term $\boldsymbol{\varepsilon}_{k}$ with covariance matrix $\mathbf{R}$ for the solution of each ensemble member $j$ (to assure sufficient spread), $\mathbf{b}$ is solved for each ensemble from

$$
\left(\mathbf{H}_{k} \mathbf{P}_{k}^{b} \mathbf{H}_{k}^{T}+\mathbf{R}_{k}\right) \mathbf{b}_{j, k}=\left(\mathbf{y}_{k}+\boldsymbol{\varepsilon}_{j, k}-\hat{\mathbf{y}}_{j, k}\right)
$$

where

$$
\mathbf{H}_{k} \mathbf{P}_{k}^{b} \mathbf{H}_{k}^{T}=\frac{\mathbf{q}_{k} \mathbf{q}_{k}^{T}}{N-1}
$$

and

$$
\mathbf{q}_{k}=\mathbf{H}_{k}\left(\hat{\mathbf{X}}_{k}^{b}-\overline{\hat{\mathbf{X}}}_{k}^{b}\right)=\left(\hat{\mathbf{Y}}_{k}-\overline{\hat{\mathbf{Y}}}_{k}\right)
$$

The matrix $\hat{\mathbf{Y}}_{k}$ contains the predicted observation vector for each of the respective ensemble members. In this case it is not necessary to solve for $\mathbf{H}$ either, and the updates are made individually to each of the ensemble members. Finally, $\mathbf{B}$ can be estimated from

$$
\mathbf{B}_{k}^{T}=\frac{\left(\hat{\mathbf{X}}_{k}^{b}-\overline{\hat{\mathbf{X}}}_{k}^{b}\right)}{N-1} \mathbf{q}_{k}^{T} .
$$

Reichle et al. (2002b) applied the Ensemble Kalman filter to the soil moisture estimation problem and found it to perform as well as the numerical Jacobian approximation approach to the Extended Kalman filter, with the distinct advantage that the error covariance propagation is better behaved in the presence of large model non-linearities. This was the case even when using only the same number of ensembles as required by the numerical approach to the Extended Kalman filter, i.e., $n+1$. 


\subsection{Dynamic Observer Assimilation Methods}

4D-Var: In its pure form, the 4-D (3-D in space, 1-D in time) "variational" (otherwise known as Gauss-Markov) dynamic observer assimilation methods use an adjoint to efficiently compute the derivatives of the objective function $J$ with respect to each of the initial state vector values $\mathrm{x}_{0}$ (see the chapter Variational Assimilation, Talagrand). This adjoint approach is derived by defining the Lagrangian functional $\mathcal{L}$ as the adjoining of the model to the cost function $J$ - Eq. (3), using Lagrange multipliers $\lambda$

$$
\mathcal{L}=J+\sum_{k=0}^{N-1} \lambda_{k+1}^{T}\left[\mathbf{x}_{k+1}-\mathcal{M}_{k}\left(\mathbf{x}_{k}, \mathbf{u}_{k}\right)\right]
$$

where ideally the second term is zero; this term guides the state estimates within the range specified by the model dynamics. Thus the Lagrange multiplier is chosen such that $\nabla \mathcal{L}=0$ and $\lambda_{N}=0$, yielding (i.e., backward pass)

$$
\lambda_{k}=\mathbf{M}_{k}^{T} \lambda_{k+1}-\mathbf{H}_{k}^{T} \mathbf{R}_{k}^{-1}\left(\mathbf{y}_{k}-\hat{\mathbf{y}}_{k}\right) .
$$

The derivative of the objective function is given from the Lagrange multiplier at time zero by $-\lambda_{0}^{T}$ (Castelli et al. 1999; Reichle and McLaughlin 2001; Reichle et al. 2001). Note that $\mathbf{M}^{T}$, the adjoint operator, is derived from the tangent linear model in Eq. (5), and effectively needs to be saved during the forward pass (Bouttier and Courtier 1999). Solution to the variational problem is then achieved by minimization and iteration. In practical applications the number of iterations is usually constrained to a small number. While "adjoint compilers" are available (see http://www.autodiff.com/tamc/) for automatic conversion of the non-linear forecast model into a tangent linear model, application of these is not straightforward. It is best to derive the adjoint at the same time as the model is developed.

Given a model integration with finite time interval, and assuming a perfect model, 4D-Var and the Kalman filter yield the same result at the end of the assimilation time interval. Inside the time interval, 4D-Var is more optimal, because it uses all observations at once (before and after the time step of analysis), i.e., it is a smoother. A disadvantage of sequential methods is the discontinuity in the corrections, which causes model shocks. Through variational methods, there is a larger potential for dynamically based balanced analyses, which will always be situated within the model climatology. Operational 4D-Var assumes a perfect model: no model error can be included. With the inclusion of model error, coupled equations are to be solved for minimization. Through Kalman filtering it is in general simpler to account for model error.

Both the Kalman filter and 3D/4D-Var rely on the validity of the linearity assumption. Adjoints depend on this assumption and incremental 4D-Var is even more sensitive to linearity. Uncertainty estimates via the Hessian are critically dependent on a valid linearization. Furthermore, with variational assimilation it is 
more difficult to obtain an estimate of the quality of the analysis or of the state's uncertainty after updating.

In the framework of estimation theory, the goal of variational assimilation is the estimation of the conditional mode (maximum a posteriori probability) estimate, while for the Kalman filter the conditional mean (minimum variance) estimate is sought.

Hybrid assimilation methods have been explored in which a sequential method is used to produce the a priori state error or background error covariance for variational assimilation.

\subsection{Challenges in Land Surface Data Assimilation}

In order for the "optimal" assimilation techniques to be truly optimal, the error characterization should be almost flawless. Therefore, recent studies have focused on the first and second order error characterization in land surface modelling. Typically, either model predictions or observations are biased. Studies by Reichle and Koster (2004), Bosilovich et al. (2007) and De Lannoy et al. (2007a, b) scratch the surface of how to deal with these biases in land surface modelling. The second order error characterization is of major importance to optimize the analysis result and for the propagation of information through the system. Tuning of the error covariance matrices has, therefore, gained attention with the exploration of adaptive filters in land surface modelling (Reichle et al. 2008; De Lannoy et al. 2009).

Furthermore, it is important to understand that land surface data assimilation applications are dealing with non-closure or imbalance problems, caused by external data assimilation for state estimation. In a first attempt to attack this problem, Pan and Wood (2006) developed a constrained Ensemble Kalman filter which optimally redistributes any imbalance after conventional filtering. They applied this technique over a $75,000 \mathrm{~km}^{2}$ domain in the US, using the terrestrial water balance as constraint.

\section{Assimilation of Land Surface Observations}

Estimation of the land surface state has mainly been focused on the soil and snow water content and temperature. The observations used to infer state information range from direct field measurements of these quantities to more indirectly related measurements like radiances or backscatter values in remote sensing products. A few studies have also tried to assimilate state-dependent diagnostic fluxes, like discharge or remotely sensed heat fluxes. The success of assimilation of observations which are indirectly related to the state is largely dependent on a good characterization of the observation operator, $\mathcal{H}($.). This section refers to terminology discussed in the chapter Mathematical Aspects of Data Assimilation (Nichols). 


\subsection{Soil Moisture Observations}

\subsubsection{Direct Insertion}

At the point scale, Heathman et al. (2003) directly inserted daily gravimetric ground measurements of surface soil moisture $(0-5 \mathrm{~cm})$ as a surrogate for remote sensing data to estimate the profile water content $(0-60 \mathrm{~cm})$ at four locations in a large watershed. Four soil layers were modelled of $15 \mathrm{~cm}$ each and an additional fifth layer was a top $5 \mathrm{~cm}$ layer. The results were compared to time domain reflectometer (TDR) measurements. They found no significant improvement in soil water estimates below $30 \mathrm{~cm}$ depth. They also stated that daily observations were needed for good results.

Montaldo et al. (2001) presented an operational assimilation framework for crudely assimilating surface soil moisture measurements in a simple SVAT model: biases between observed and modelled time rates of change of surface soil moisture were used to quantify biases between modelled and actual root-zone-average soil moisture contents. They tested the framework for misspecification of a parameter, the saturated hydraulic conductivity, and for uncertain initial conditions, and found improvements through assimilation. The assimilation frequency was found to be of limited importance: infrequent corrections were reported to be sustained by the internal model dynamics. It should be noted that data assimilation intervals of 3-120 h only were considered. In a subsequent study, Montaldo and Albertson (2003) recognized that large errors in the saturated hydraulic conductivity resulted in persistent bias in the predictions and proposed a multi-scale (in time) assimilation system in which the root zone soil moisture was updated at the observation time scale and the parameter was adjusted at a coarser time-scale, since it would be questionable to adapt parameters as frequent as observations would be available.

At a coarser scale, Li and Islam (1999) assimilated gravimetric measurements of soil moisture as a surrogate for remote sensing data through daily hard-updating over a single unit region in a four-layer model. They used site-averaged data over an area of $15 \times 15 \mathrm{~km}^{2}$. They focused on the role of surface soil moisture assimilation in the partitioning of fluxes and found that assimilation of surface soil moisture had a positive impact, under the assumption of zero error in the observations and forcings. For deeper layers the improvement in profile predictions decreased. They speculated that in the presence of commonly encountered random measurement errors, daily assimilation of microwave measurements of soil moisture would not improve the profile estimate and the partitioning of the fluxes. They studied three different frequencies of assimilation: 12, 24 and $48 \mathrm{~h}$ and found a limited sensitivity to the data assimilation frequency, with slightly better results for more intensive data assimilation.

\subsubsection{Statistical Correction, Nudging, Optimal Interpolation}

Houser et al. (1998) compared different assimilation strategies with TOPLATS, using off-line inverted remotely sensed microwave observations in a distributed 
model set-up. They found that Newtonian nudging assimilation was preferable to statistical corrections assimilation and optimal interpolation. Pauwels et al. (2001) assimilated real ERS images in TOPLATS to assess the impact on discharge predictions. Through comparison of results from a nudging and a statistical correction technique in both a lumped and a distributed model version, they found that assimilating the statistics (spatial mean and variance) of remote sensing data in lumped models sufficed to improve discharge predictions. Paniconi et al. (2003) used the Newtonian nudging technique in a pure synthetical study over an idealized artificial study area to assimilate surface soil moisture in a 3-D Richards equation-based distributed model. They stated that four-dimensional weighting functions used in the nudging approach provide a simple way to incorporate knowledge on characteristic length scales and spatio-temporal variability of the state variables. Hurkmans et al. (2006) tested the sensitivity of this dynamical relaxation technique for the different nudging parameters.

\subsubsection{Kalman Filter}

Point profile estimation: Entekhabi et al. (1994) were among the pioneers to estimate time-dependent $1 \mathrm{~m}$ soil moisture and temperature profiles under bare soil from synthetic measurements of microwave and infrared radiation, using an EKF. The direct use of emitted radiation by including a complex observation model, i.e., a radiative transfer model (RTM), in the Kalman filter procedure was a key significant feature of their study. They found that starting from an intentionally poor initial guess and with hourly updates, the estimates improved in time and, eventually, the dynamics of the true profile were captured down to depths far beyond the penetration depth of the observations. This work, with inclusion of an RTM in the estimation procedure, was extended by Galantowicz et al. (1999) using daily field data of Lband radio brightness over a period of 8 days at a Beltsville Agricultural Research Center bare soil test plot, and synthetic data over a 4 month period at an observation interval of 3 days. They studied a soil column of $1 \mathrm{~m}$ depth with 31 layers. They initialized the a priori state error covariance matrix $\mathbf{P}^{b}$ as a diagonal matrix with large diagonal values. Through time, deeper soil moisture could be retrieved as the interdepth covariances had been adapted through modelled moisture percolation and redistribution (i.e., the off-diagonal elements increased). Likewise, Crosson et al. (2002) estimated soil moisture distributions by assimilating brightness temperatures with a Kalman filter incorporating an RTM. Each time brightness temperature data were available, the modelled soil moisture profiles were used as input in a forward RTM and combined with the observations to update the soil profile.

Active microwave observations were assimilated by Hoeben and Troch (2000) in a synthetic study to estimate the soil profile with an EKF. They studied the effect of system and observational noise and found that in the presence of realistic system noise, the retrieval is feasible with an acceptable accuracy, but for observational noise which approaches the real world satellite errors, the accuracy of the profile retrievals drops to the level of the reference run without data assimilation. Based 
on their investigation of the update interval (from hourly to every 2 days), they suggested that daily radar images would be necessary for accurate updates.

Wendroth et al. (1999) applied a Kalman filter to the surface layer of a 3-layer $(10,30$ and $50 \mathrm{~cm})$ soil profile and found that assimilation of pressure head observations improved the soil moisture estimates for deeper layers, even when the model showed clear shortcomings in the simulation of evapotranspiration.

Walker et al. (2001a) discussed a 1-D soil moisture profile retrieval by assimilation of synthetic near-surface soil moisture ground measurements, which greatly simplified the observation operator. The KF scheme was found to be superior to a direct insertion scheme. They found that the observation interval was not important for profile estimation with a Kalman filter, when the forcing data was accurate (to ensure correct predictions). The observation depth did not have a significant effect on the profile retrieval time with a Kalman filter. This synthetic study was extended by a study using real field data from the Nerrigundah catchment. Walker et al. (2001b) developed a simplified soil moisture model (ABDOMEN) and studied assimilation of near-surface soil moisture measurements for profile soil moisture retrieval. They found that the presence of bias hampered the success of the Kalman filter procedure and that less frequent updating improved the total soil moisture profile, while near-surface soil moisture was poorly predicted. Therefore, they stressed the need for an appropriate forecasting model and suggested that assimilation of near-surface soil moisture would be useful only to correct for errors in soil moisture forecasts as result of errors in initial conditions and/or atmospheric forcing data, and not as a result of errors in the physics of the soil moisture model.

Lumped spatial field estimation: Georgakakos and Baumer (1996) used the Kalman filter to assimilate basin-integrated ground surface soil moisture observations to estimate soil moisture in a deeper layer with a simple conceptual 2-layer model. Through a sensitivity study, they found that even when the upper soil water measurements contained substantial (added) noise, the estimates of lower soil water contents were improved.

In the framework of the European AIMWATER project on the Seine catchment, the assimilation of Synthetic Aperture Radar (SAR) observations was considered (Francois et al. 2003), mainly aiming at updating discharge flows. Oudin et al. (2003) concluded that the current SAR instruments have a repeat time that is too low to enhance their parameter updating procedure efficiency. In a very simple study on four subcatchments of the Seine catchment, they also found that the optimal soil moisture depth (of TDR measurements) for parameter updating was dependent on the subcatchment considered. Streamflow and soil moisture were estimated for the same study area by a sequential Kalman filter by Aubert et al. (2003). They simulated time repetitivity of remote sensing data by eliminating part of their TDR measurements and found that through assimilation the efficiency remained higher than without assimilation for a repeat time as high as 1 week.

Crow (2003) found successful results through daily assimilation of brightness temperature observations via an EnKF to correct for the impact of poorly sampled rainfall data on land surface predictions of root-zone soil moisture and surface energy fluxes. Plot-scale simulations were run with the TOPLATS SVAT on 2 
sites, both for 2 approaches: using synthetic data in an identical twin data assimilation experiment (these experiments are discussed in chapter Observing System Simulation Experiments, Masutani et al.), and using real data obtained during the Southern Great Plains 1997 (SGP97) experiment. They indicated that an increased observation frequency (up to once every 5 days) reduced the sensitivity of the results to the frequency in rainfall observations. The filter performance was evaluated with regard to the assumptions that underlie the optimality of the KF update equations. Crow and Wood (2003) also applied an EnKF to assimilate remotely sensed soil brightness temperatures using point-scale TOPLATS results at 2 sites to compensate predictions in surface latent heat flux and root-zone water storage for errors due to use of climatological rainfall data. They discussed inadequacies in model physics, and the contrasts of spatial support between model predictions and sensor retrievals. They found little improvement when increasing the ensemble sizes and suggested that for larger ensemble sizes, alternative error sources and shortcomings in the reference results themselves are more important than the errors arising from finite ensemble sizes.

Wilker et al. (2006) conducted a single column (single site) SGP97 assimilation experiment with an EKF and the operational Numerical Weather Prediction (NWP) system of the European Centre for Medium-Range Weather Forecasts (ECMWF). They showed that, in the case of non-uniform soil moisture profiles, the typical top layer vertically integrated simulated soil moisture will introduce errors, because the top surface layer is not resolved properly to represent the soil moisture corresponding (through a forward operator) to the observed brightness temperature. Therefore, they advised to correct the observations for this representativeness error.

Distributed spatial field estimation: Distributed applications of the Kalman filter are often limited by computational constraints and hence reformulated as a collection of individual 1-D applications.

Reichle et al. (2002a, b) compared synthetic experiments results using an EnKF to the variational approach and the Extended Kalman filter, respectively. They gave insights into the theoretical and practical aspects of these techniques, and illustrate them for distributed case studies with different LSMs over different testbed regions in the northern USA.

Margulis et al. (2002) discussed the EnKF in a field test with assimilation of real brightness data into a 1-D model, applied over the study area of the SGP97 experiment. They aggregated the observational data to $4 \times 4 \mathrm{~km}^{2}$ pixels to reduce the computational load. Through assimilation, they found that surface soil moisture and latent heat flux estimates were nearly always closer to ground truth measurements and more consistently within the measurement error bars than the open loop simulations (i.e., without data assimilation).

While most studies on soil moisture assimilation focused on filtering techniques, Dunne and Entekhabi (2005) argued that the soil moisture estimation problem should be treated as a reanalysis-type problem, as observations beyond the estimation time still provide useful information, as long as subsequent precipitation events are avoided. Dunne and Entekhabi (2005) compared the performance of an Ensemble Kalman smoother to that of an EnKF in an Observing 
System Simulation Experiment (OSSE; see chapter Observing System Simulation Experiments, Masutani et al.), using a 1-D model (uncorrelated grid cells) and an RTM to merge model results with synthetic brightness data. Because of the occurrence of precipitation, a hybrid smoother/filter approach was presented to break the study interval into a series of smoothing windows of single drydowns. They found that including future observations could improve the initial conditions at depth, resulting in improved latent heat flux estimates. Dunne and Entekhabi (2006) compared the EnKF and its smoother variant for estimation of soil moisture and surface energy fluxes by assimilation of real L-band brightness data over the SGP97 study area.

Walker and Houser (2001) avoided spin-up of a land surface model by initializing soil moisture through a 1-D EKF of synthetic near-surface soil moisture data over the North American continent. This study illustrated the essential goal of data assimilation for state estimation, i.e., find the best state (analysis, initial condition) to initiate future predictions.

Walker and Houser (2004) addressed requirements for soil moisture satellite accuracy, repeat time and spatial resolution through a twin experiment with a 1-D EKF in the Catchment model with 3 moisture prognostic variables. Each catchment (average area of $4,400 \mathrm{~km}^{2}$ ) was taken as a calculation unit. The resolution and accuracy requirements were found to be much more important than repeat time. They found that the soil moisture observations should have accuracy better than $5 \mathrm{vol} \%$; the resolution of the assimilated data should be less than the resolution of the land surface model; and repeat times should be from 1 to 5 days.

Crow and van Loon (2006) applied TOPLATS to a watershed, assuming that sub-basin scale variability in water table depth was solely driven by the local soiltopography index. In a synthetic filtering experiment (without any need for detailed spatial validation), they showed possible pitfalls with adaptive filtering, the consequences of an improper selection of model error and the benefit of combined soil moisture and runoff data for adaptive filtering.

Some studies have tried to approximate the full 3-D problem by sophisticated mathematical techniques. Reichle and Koster (2003) compared the performance of a 1-D and 3-D EnKF in a synthetic twin experiment with the Catchment model, considering only 3 state variables related to soil moisture per catchment. Since non-zero off-diagonal elements would necessitate a simultaneous update for all catchments or grid cells, this would require immense computational effort. However, for continental or global soil moisture fields, the scale for horizontal error correlations is much smaller than the domain size, and covariance localization can be used in combination with a parallel implementation. They found that information was spread from observed to unobserved catchments, when taking into account the horizontal error correlations.

Walker et al. (2002) applied a 3-D KF to assimilate near-surface measurements from the Nerrigundah catchment for soil moisture profile estimation in a full 3-D soil moisture model. Because the spatial coupling necessitated a computationally efficient methodology to propagate the state error covariances, a simplified system dynamics approach was used. 
De Lannoy et al. (2009) implemented a full 3-D adaptive EnKF system, which was parallellized both in the forecast part and the update part, but not in the calculation of the Kalman gain. This allowed finding spatial error correlations between individually simulated soil profiles, which could then be used to propagate observational information in a single profile to all other profiles in a small-scale field.

\subsubsection{D/4D-Var}

Point scale estimation: Calvet et al. (1998) assimilated field measurements of surface soil moisture through a (strong constraint) variational data assimilation approach, and found that 4 or 5 observations spread over an assimilation window of 15 days were enough to retrieve total soil water content by inverting the Interactions between Soil, Biosphere and Atmosphere (ISBA) scheme, given correct knowledge of the forcings. Use of the soil temperature was more of a problem, because it was not always found to be sensitive to the total water content. Their study was conducted at one site at the point scale and used averaged gravimetric soil moisture measurements $(0-5 \mathrm{~cm})$ during an intensive observation period (IOP) of 30 days. Wingeron et al. (1999) used the same ISBA model in combination (variational) with a surface soil moisture data set of 3 months during the vegetation cycle of soybean to study requirements for the use of remote sensing measurements of soil moisture to accurately estimate the root zone soil moisture.

Lumped spatial field estimation: Li and Islam (2002) applied a model inversion technique suggested by Calvet et al. (1998) for assimilation of surrogate remotely sensed data (averaged gravimetric samples) over a $15 \times 15 \mathrm{~km}^{2}$ area, and found that the estimation of surface soil moisture was very sensitive to the initialization of deeper layer soil moisture. They also found that initialization of the soil moisture profile in such a way that it optimizes the error in the surface soil moisture, may not lead to optimal estimation of surface fluxes and accurate retrieval of deeper layer soil moisture. This was attributed to a decoupling of the surface and deeper soil moisture.

Pathmathevan et al. (2003) estimated 1-D soil moisture profiles through daily variational assimilation of microwave radiometer measurements in the Land Surface Scheme (LSS) of the Simple Biosphere Model 2 (SiB2) with 3 layers of soil moisture. No adjoint model was developed, and a heuristic optimization technique, simulated annealing, was used instead to minimize a variational cost function.

Distributed spatial field estimation: Reichle and McLaughlin (2001) discussed a pioneering synthetic study on the feasibility of a 4-D variational assimilation algorithm, where they used a representer method to account for both model and observational error. They developed a relatively simple model to allow development of a numerically well-behaved adjoint model. A non-linear radiative transfer model (RTM) was included on-line in the assimilation procedure to allow direct assimilation of brightness temperatures. In a closely related 4-D weak constraint variational data assimilation study, Reichle et al. (2001) showed that synthetic radio 
brightness measurements could be used to estimate soil moisture at scales finer than the resolution of the brightness images, provided that information on land surface characteristics and micro-meteorological inputs were available.

\subsection{Soil Temperature Observations}

Soil temperature can be used to update the total land surface state, including soil moisture, and its dependent land surface fluxes, like evapotranspiration. Lakshmi (2000) used surface temperature to validate model surface temperatures and adjust model simulated soil moisture. A two-layer land surface model was applied to 66 $1^{\circ} \times 1^{\circ}$ pixels over the area of the Red-Arkansas study region. For a period of 1 year, radiance data, which were available as gridded fields and converted to temperature data, were equally weighted with model simulations twice a day to obtain an adjusted estimate of the soil temperature. They found that, through assimilation, on average (over the studied area) improved estimates for soil moisture were found and the effect of errors in the forcings was reduced. Spatially distributed comparisons of soil moisture fields showed a reduced difference between observed (satellite brightness data converted to soil moisture through an RTM) and simulated soil moisture, and also a reduced standard deviation in the difference.

Land surface temperature may be used to provide estimates of components of the surface energy balance and land surface control on evaporation. Kumar and Kaleita (2003) used an EKF to assimilate top layer temperature measurements for the estimation of a soil temperature profile at a 1-point site at the western edge of the Little Washita River Watershed. Data were assimilated at $1 / 2$ and $24-h$ increments in a soil column of 6 layers. When data were available every $1 / 2 \mathrm{~h}$, the lower layers responded much more rapidly to the inclusion of observed data. They also found that the correlation structure between the different layers was more complicated than could be described with a simple diagonal matrix.

Castelli et al. (1999) applied a variational methodology with an adjoint to assimilate area-averaged soil surface temperature for retrieving surface fluxes and a soil moisture index, which depended on soil wetness and aerodynamic conditions.

Caparrini et al. (2004) discussed the determination of turbulent heat fluxes by variational assimilation of remotely sensed land surface temperature into a surface energy balance model and showed an application to a large area within the US Great Plains. They showed how to assimilate measurements with varying scales and with overlapping coverages.

Boni et al. (2001) assimilated half-hourly in situ ground temperature observations to generate a reference (validation truth) to explore the value of satellite data assimilation by a variational technique with an adjoint. The performance was found to vary with the timing of the satellite overpass and the estimation was most improved when measurements were available close to the time of peak ground temperature. The study was conducted on 2 sites (not distributed in space) within the SGP97 
experiment area. The satellite brightness data were area-averaged and converted to temperatures off-line, before assimilation.

\subsection{Low-Level Atmospheric Observations}

Research on the assimilation of screen-level measurements of relative humidity and temperature (Bouttier et al. 1993; Viterbo and Beljaars 1995) has mostly focused on variational studies, which tried to find an optimal initial state by searching for a best match between the resulting model simulations and the observations. These low-level atmospheric data have been used because they are widely available and very sensitive to soil moisture. Generally, soil moisture estimates have been integrated over the root zone. Mahfouf (1991) introduced the assimilation of low-level atmospheric variables such as relative humidity and air temperature to initialize soil moisture for improved short- and medium-range weather forecasts. He tested a strong constraint variational approach and a sequential nudging approach, which was a statistical algorithm based on linear regressions. Based on this work, several authors investigated these two approaches with atmospheric observations. Bouttier et al. (1993), Hu et al. (1999), Douville et al. (2000), Pleim and Xiu (2003), for example, explored and adapted the sequential nudging technique, while the studies of Callies et al. (1998), Bouyssel et al. (1999) and Hess (2001) followed the variational approach. Douville et al. (2000) found that the nudging technique was very sensitive to model bias. Rhodin et al. (1999) applied the technique of Callies et al. (1998) to a regional weather forecast model, while neglecting all horizontal correlations to facilitate the 3-D assimilation problem. It should be remarked that in all these studies, soil moisture has little physical meaning and it is rather used as a parameter in NWP models. Assimilation of atmospheric variables is interesting because these data are readily available in an operational system for NWP, but Bouyssel et al. (1999), for example, reported that operational implementation of surface analyses is difficult with these kind of data in general weather conditions including precipitation, cloudy conditions or large-scale advection. Seuffert et al. (2004) found that synergistic assimilation of screen-level parameters and microwave brightness temperatures yielded more consistent results than assimilation of either observation type separately.

\subsection{Land Surface Flux Observations}

To date, only a few studies have explored the assimilation of remotely sensed land surface flux observations. Schuurmans et al. (2003) converted $1 \times 1 \mathrm{~km}^{2}$ resolution remotely sensed data into latent heat flux estimates to assimilate them into a distributed hydrological model to improve the model water balance. They applied an optimal interpolation scheme (constant gain Kalman filter), to study the spatial 
distribution of model latent heat flux estimates and found improvements in areas with higher elevations.

\subsection{Vegetation-Based Observations}

Specification of seasonal variations of vegetation properties can significantly affect the simulation of several near-surface variables. Mahfouf and Viterbo (2001) indicated that the difficulty in capturing the variability of vegetation is the relation between satellite reflectances to input parameters, such as leaf area index (LAI) and albedo in land surface schemes. Pauwels et al. (2007) have shown that through assimilation of LAI values and soil moisture observations the results from coupled hydrological/crop growth models can be improved.

\subsection{Discharge Observations}

The possibility to use discharge data to update the state variables of a hydrological model has been explored, either using only discharge data (Pauwels and De Lannoy 2006; Vrugt et al. 2006; Komma et al. 2008), or a combination of discharge and soil moisture data (Aubert et al. 2003).

A fundamental difference between the assimilation of runoff rates and the assimilation of other variables (for example soil moisture values) is the fact that observed catchment runoff rates are the integrated result of runoff generating processes occurring between the moment of the observation and a number of time steps before the observation. This implies that, if a discharge observation at a certain time is assimilated, the state variables of a number of time steps before the assimilation need to be updated as well, to assure fully optimized discharge forecasts.

\subsection{Snow Water Equivalent/Snow Cover Observations}

Snow on land is an important variable affecting the global energy and water budgets, because of its high albedo, low thermal conductivity, considerable spatial and temporal variation and medium-term capacity for water storage. The amount of water in snow, i.e., the snow water equivalent (SWE), can be observed in situ or derived from brightness temperatures, e.g. obtained from the Advanced Microwave Scanning Radiometer - EOS (AMSR-E) or Special Sensor Microwave/Imager (SSM/I). Another commonly used observation is the snow cover area or fraction (SCA or SCF), which can be measured relatively accurately through remote sensing, e.g. with the Moderate Resolution Imaging Spectroradiometer (MODIS). Some challenges related to snow assimilation have been discussed by Walker and Houser (2005). 
Cosgrove and Houser (2002) showed that large water balance errors could occur when directly inserting SWE observations into imperfectly modelled snow melting processes. Assimilation of remotely sensed SWE was studied in a synthetic study with a 1-D EKF by Sun et al. (2004). Slater and Clark (2006) assimilated real SWE data in a conceptual model with an Ensemble Square Root Kalman filter and showed that merging of information was better than either the model results or interpolated observations. Durand and Margulis (2006) conducted a feasibility study using a variety of point-scale synthetically generated observations in combination with a LSM and a RTM to assess the contribution of each channel (brightness temperature $T_{b}$ of $\mathrm{SSM} / \mathrm{I}, T_{b}$ of AMSR-E, and broadband albedo from MODIS satellite products) to recovering the true SWE. Other interesting follow-up studies on SWE assimilation were reported by Durand and Margulis (2007, 2008). Dong et al. (2007) used a 1-D EKF to assimilate SWE data, which were obtained after conversion of Scanning Multichannel Microwave Radiometer (SMMR) brightness temperature to SWE. They excluded data with potential high errors. Andreadis and Lettenmaier (2006) found that assimilation of AMSR-E SWE data into the VIC model was not very successful, due to errors in the AMSR-E product. De Lannoy et al. (2010) successfully downscaled AMSR-E-scale synthetic SWE to retrieve fine-scale variability in several 1-D and 3-D EnKF setups.

Modelling results by Déry et al. (2005) showed improved runoff timing and runoff amounts when MODIS fractional snow cover data were incorporated. Rodell and Houser (2004) used satellite-derived MODIS SCA to update the SWE in a land surface model by a rule-based assimilation scheme, but they found that SCA contained very little information about SWE. Andreadis and Lettenmaier (2006) applied an EnKF to update SWE by assimilation of SCA from MODIS data and used a simple snow depletion curve as the observation operator to relate SWE to SCA.

\subsection{Ground Water Storage Observations}

Subsurface observations have only seen limited use to estimate the land surface state, most likely because using these observations only yields a limited observability of the land surface system (the information content in the observations does not allow to fully reconstruct the land surface state). Zaitchik et al. (2008) assimilated Gravity Recovery and Climate Experiment (GRACE)-derived monthly terrestrial water storage (TWS) anomalies for each of the four major subbasins of the Mississippi into the Catchment Land Surface Model (CLSM) using an Ensemble Kalman smoother, and obtained improved water storage and fluxes dynamics.

Several applications of the Kalman filter in the field of groundwater modelling have been studied by Eigbe et al. (1998) and Porter et al. (2000), but most studies do not consider the land surface state, but rather focus on the inverse problem of determining the hydraulic properties, assuming a perfect groundwater model. 


\section{Case Studies}

Significant advances in hydrological data assimilation have been made over the past decade from which we have selected a few case studies to demonstrate the utility of hydrological data assimilation.

\subsection{Case Study 1: Soil Moisture Assimilation}

The estimation of soil moisture profiles has received considerable attention, because a correct assessment of the soil moisture state is crucial to estimate the partitioning of surface fluxes, for weather predictions and climate analyses. For this case study, the EnKF was used with the Community Land Model (CLM2.0) to assimilate ground measurements for soil moisture profile estimation (De Lannoy et al. 2007a). The focus was on the determination of the best observation conditions for assimilation and on the optimization of the method with real data.

An Ensemble Kalman filter for state estimation and a dynamic bias estimation algorithm was applied to estimate individual soil moisture profiles in a small corn field with the CLM2.0 model through the assimilation of measurements from capacitance probes. Both without and with inclusion of forecast bias correction, the effect of the assimilation frequency, the assimilation depths, and the number of observations assimilated per profile, were studied. Assimilation of complete profiles had the highest impact on deeper soil layers, and the optimal assimilation frequency was about 1-2 weeks, if bias correction was applied (Fig. 4). Without bias correction, a higher assimilation frequency always further improved the results (Fig. 4). Bias correction on top of state estimation extracts more information from the observations and thus a limited assimilation frequency is sufficient for optimal results. The optimal assimilation depth depended on the calibration results. Assimilation in
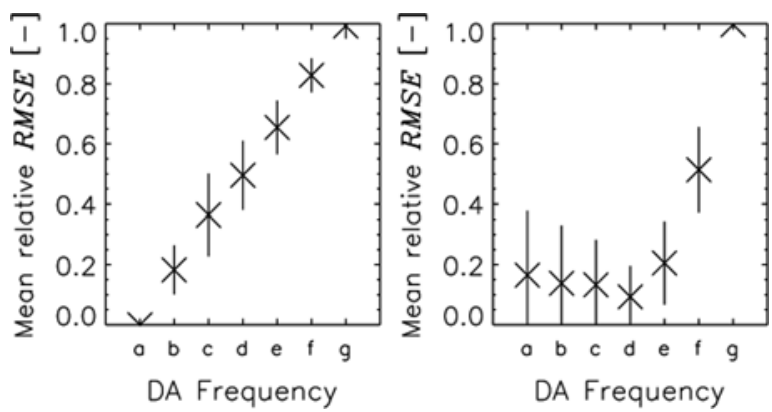

Fig. 4 Mean (and spatial standard deviation over 36 field profiles) relative profile-integrated RMSE (root mean square error) for profile assimilation with (left) EnKF and (right) EnBKF (with inclusion of dynamic forecast bias estimation) as a function of varying numbers of observations in time. Assimilation intervals a, b, c, d, e, f and g are 1, 2, 4 days, 1, 2, 4 and 8 weeks, respectively 


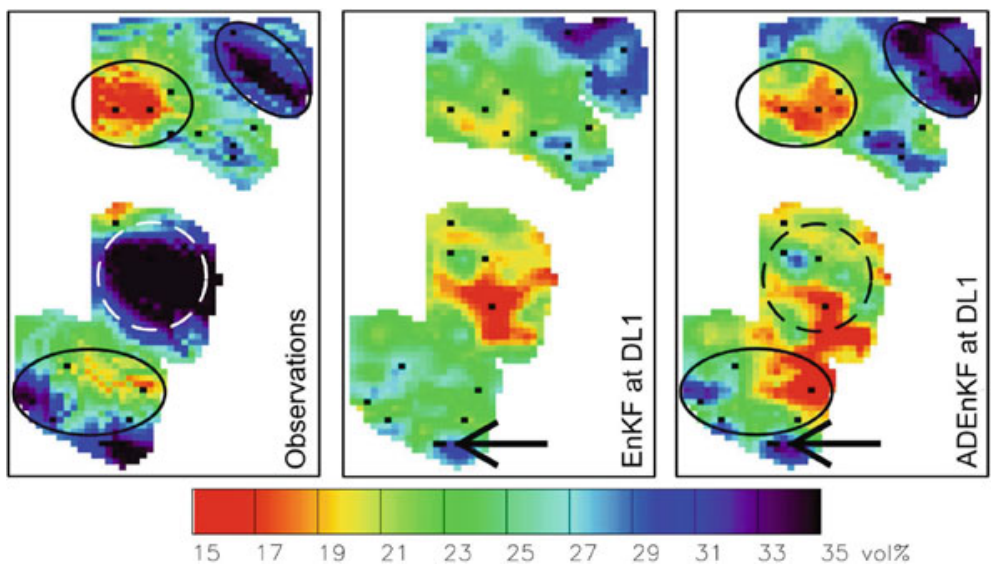

Fig. 5 Spatially interpolated fields of (left) observations, (middle) ensemble mean forecasts and single-profile EnKF analysis at the indicated point location only and (right) full 3-D adaptive EnKF analyses after assimilation at the indicated point location only. The black dots indicate observed locations. The full ellipses show areas with an improved impact through adaptive 3-D EnKF filtering. The simulated (middle panel) moisture is underestimated in the dashed circular area and the adaptive 3-D filter (without bias estimation) cannot overcome the large bias

the surface layer had typically less impact than assimilation in other layers. In general, the correct propagation of the innovations for the bias-blind state as well as for the bias filtering from any layer to other layers was insufficient. The approximate estimation of the a priori (bias) error covariance and the choice of a zero-initialized persistent bias model made it impossible to accurately estimate the bias in layers for which no observations were available.

In a subsequent study by De Lannoy et al. (2009), horizontal propagation of assimilated profiles information in space was achieved after optimizing (training) spatial forecast error covariances in an adaptive three-dimensional (3-D) EnKF. In Fig. 5 an interpolated field of point-scale measurements is shown, together with a one-profile EnKF analysis and a 3-D EnKF analysis after spatial error covariance training. The one-profile EnKF updates all observed and unobserved profile layers only at the assimilation location. The full 3D EnKF spreads this information to all unobserved locations in space.

These studies show the importance of both a good first and second order error characterization for Kalman filtering with real data, i.e. soil moisture forecast bias estimation and spatial forecast error covariance estimation.

\subsection{Case Study 2: Streamflow Assimilation}

Rüdiger et al. (2005) have shown the potential for assimilating streamflow measurements to retrieve soil moisture. A synthetic study was undertaken on three nested catchments (sequentially draining into each other) within the Goulburn River 
experimental catchment in south-eastern Australia (Rüdiger et al., 2007). Three scenarios are presented: (i) only streamflow observations are available for the outlet of the lowest catchment; (ii) streamflow observations are not available and surface soil moisture observations are only available for one of the catchments under the assumption that the other two catchments are too densely vegetated to allow a reliable retrieval of soil moisture; and (iii) streamflow observations are available for the lower catchment and surface soil moisture observations for the middle catchment. This synthetic study identifies the potential of using different observations, where and when available, for the retrieval of soil moisture initial states. The assimilation type here is performed as an initial state optimization through minimizing an objective function penalizing the deviation from the observed soil moisture and/or streamflow over some assimilation window.

The assessment is based on a comparison between assimilated, truth and nonassimilated (control) simulations in Fig. 6. In the control simulation, the root zone soil moisture content was subjected to a wet bias. It was found that the assimilation of streamflow has a significant improvement in the retrieval of profile and root zone soil moisture in all three catchments, but displays limitations in retrieving the surface soil moisture state. In contrast, the assimilation of surface soil moisture in the lower catchment alone does not have any effect on the upstream catchments, as there
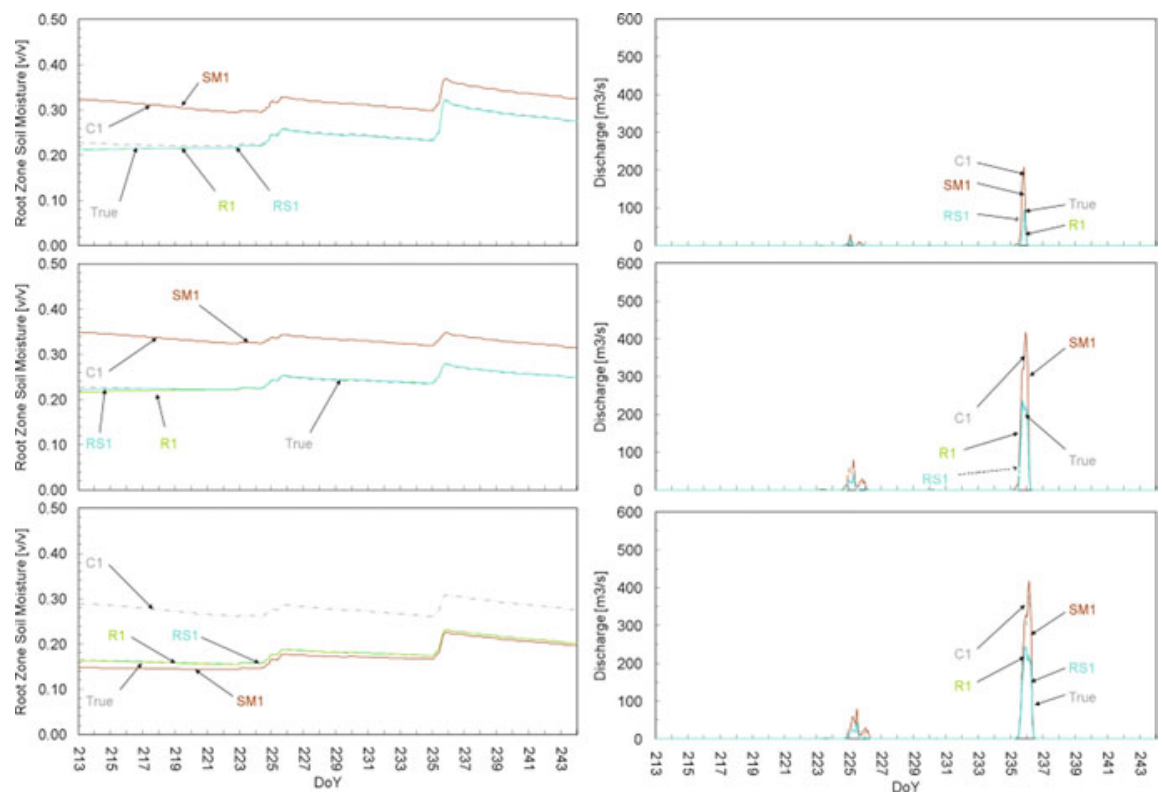

Fig. 6 Assimilation results for root zone soil moisture and runoff for (R1) discharge (observed at the lower catchment) assimilation only, (SM1) soil moisture (observed at the lower catchment) assimilation only, and (RS1) simultaneous assimilation of soil moisture (observed in the middle catchment) and discharge (lower catchment). Individual catchments are shown in rows (upper, middle, and lower catchments). $\mathrm{C} 1$ represents the control run without assimilation 
is no feedback between the downstream and upstream soil moisture and respective runoff. Finally, the joint assimilation of both streamflow and surface soil moisture observations leads to a further improvement from the streamflow assimilation alone.

The comparison between the results from the degraded and the assimilation runs show a good improvement of the overestimated soil moisture and runoff values through streamflow assimilation. The best performance is observed for the lower catchment, with slight inaccuracies for the two upstream catchments. The main difference between the "truth" observations and the assimilation run is the retrieval of the surface soil moisture content, which is underestimated. This is due to the initial surface soil moisture content not having a significant impact on the runoff and, hence, the objective function, when the profile moisture is well retrieved. While the infiltration capacity excess mechanism is still the main process contributing to runoff (runoff is only produced when saturation of the surface soil moisture is achieved), there is no runoff occurring in the first 10 days of the assimilation window, so that changes to the initial soil moisture states cannot generate runoff events. The precipitation events causing runoff occur over a short period, but during these events sufficient water is introduced into the catchment to wet up the surface layer to the point of saturation and allow runoff to be produced. Because the root zone soil moisture is accurately retrieved, all subsequent soil moisture values are close to the true observations, and, therefore, the initial value of the surface soil moisture before its saturation during the first precipitation event is irrelevant.

The study of Rüdiger et al. (2005) was undertaken as a proof-of-concept twinstudy for streamflow assimilation, in which only the initial states were perturbed. In Rüdiger et al. (2007) wet and dry biases and white noise were added to the forcing data to simulate uncertainties in the observational data base, while assuming that there is no knowledge about observational or background errors.

\subsection{Case Study 3: Snow Assimilation}

Accurate prediction of snowpack status is important for a range of environmental applications, yet model estimates are typically poor and in situ measurement coverage is inadequate. Moreover, remote sensing estimates are spatially and temporally limited due to complicating effects, including distance to open water, presence of wet snow, and presence of thick snow (Dong et al. 2005). However, through assimilation of remote sensing estimates into a land surface model, it is possible to capitalize on the strengths of both approaches (Dong et al. 2007). In order to achieve this, reliable estimates of the uncertainty in both remotely sensed and model simulated snow water equivalent (SWE) estimates are critical. For practical application, the remotely sensed SWE retrieval error is prescribed with a spatially constant but monthly varying value, with data omitted for: (1) locations closer than $200 \mathrm{~km}$ to significant open water; (2) times and locations with model-predicted presence of liquid water in the snowpack; and (3) model SWE estimates greater than $100 \mathrm{~mm}$. 

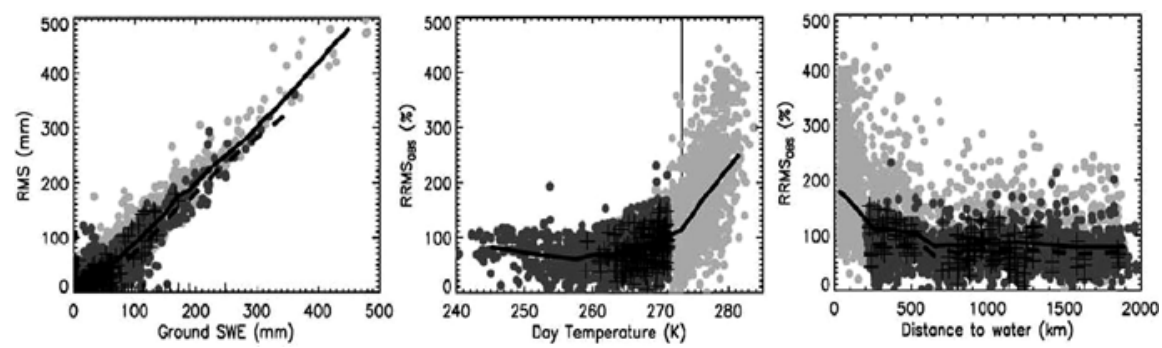

Fig. 7 SMMR passive microwave SWE retrieval root mean square (RMS) error of the in situ SWE estimates (left panel), average monthly daytime temperature (middle panel), and "distance" to water (right panel). The light grey dots show all the data and dark gray dots show the data remaining after omitting pixels closer than $200 \mathrm{~km}$ to water and with an average monthly daytime temperature above $2^{\circ} \mathrm{C}$; the lines show the mean values respectively. The pluses represent data for pixels including 5 or more ground stations

The model error is estimated using standard error propagation with a calibrated spatially and temporally constant model error contribution. The SWE estimates from assimilation were found to be superior to both the model simulation and remotely sensed estimates alone, except when model SWE estimates rapidly and erroneously crossed the $100 \mathrm{~mm}$ SWE cut-off early in the snow season.

Based on an extensive evaluation of SMMR SWE estimates Dong et al. (2005) suggest that SMMR SWE retrievals should not be used for: (1) regions within $200 \mathrm{~km}$ of significant open water bodies due to mixed pixel contamination; (2) times when monthly mean air temperature is above $2^{\circ} \mathrm{C}$ due to potential meltwater contamination; and (3) times and locations where in situ SWE values are above $100 \mathrm{~mm}$ due to microwave signal saturation (Fig. 7). Restricting the use of remotely sensed SWE on this basis was found to result in a nearly unbiased SWE estimate with a seasonal maximum RMS (root-mean-square) median error of $20 \mathrm{~mm}$.

A set of numerical experiments were undertaken by Dong et al. (2007) to evaluate the impact of assimilating quality controlled SMMR SWE retrievals on snowpack state variables. The first simulation is a straight model simulation run (i.e., without data assimilation, and referred to as the open-loop run) to show how the model performed in the absence of assimilation. The second and third simulations are two Extended Kalman filter (EKF) assimilation experiments (referred to as assimilation run-I and run-II), started with the same initial conditions as the open-loop run, but assimilating the remotely sensed SMMR SWE estimates when available. The difference between these two runs is that run-I assimilates all available SMMR SWE data while run-II only assimilates quality-controlled data. The median predicted and observed SWE estimates for pixels with five or more in situ stations are shown in Fig. 8. For the simulations starting in the middle of winter, it was found that assimilation run-II outperformed both of the other snowpack simulations, with the results from assimilation run-I approaching the unmasked SMMR SWE values. This was expected, as erroneous SWE observations when not eliminated (as in run-I), or adequately characterized by their error covariances, act to degrade the snowpack 

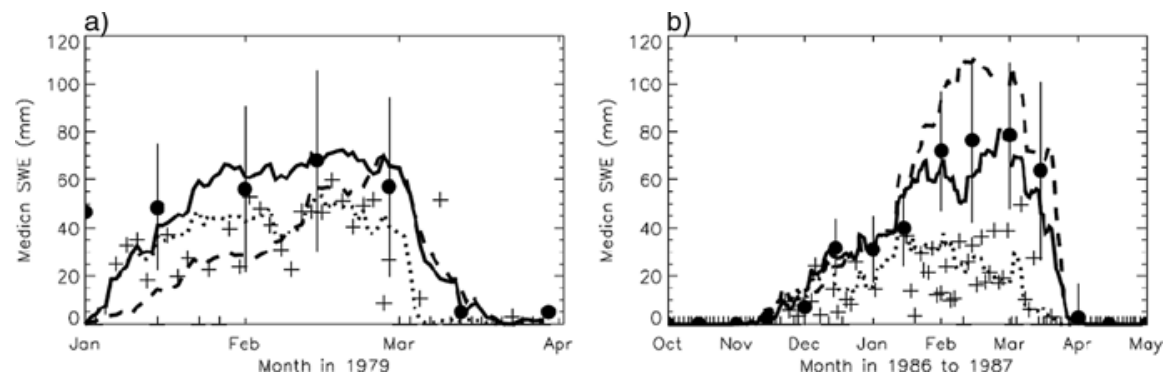

Fig. 8 Comparison of the median SWE for pixels including five or more stations; ground observations (black dots), SMMR observations (plus symbols), model forecast (dash lines), model forecast with assimilation run-I (dotted lines) and run-II (solid lines) from: (a) January to March in 1979 (left panel), and (b) July 1986-June 1987 (zoomed to the winter months from October 1986 to April 1987 - right panel). The vertical lines show the plus one and minus one standard deviation from the median of the ground observations

simulation through their assimilation. The open-loop simulation significantly underestimates the snowpack SWE throughout the entire simulation due to the zero snow initialization. The resulting median estimates from assimilation run-II are in close agreement with the ground observations. Statistical analysis shows that bias error has been largely reduced, and RMS error has been slightly reduced.

\subsection{Case Study 4: Skin Temperature Assimilation}

The land surface skin temperature state is a principal control on land-atmosphere fluxes of water and energy. It is closely related to soil water states, and is easily observable from space and aircraft infrared sensors in cloud-free conditions. The usefulness of skin temperature in land data assimilation studies is limited by its very short memory (on the order of minutes) due to the very small heat storage it represents. Radakovich et al. (2001) have demonstrated skin temperature data assimilation in a land surface model using three-hourly observations from the International Satellite Cloud Climatology Project (ISCCP) - see Fig. 9. Incremental and semi-diurnal bias correction techniques based on Dee and da Silva (1998) were developed to account for biased skin temperature forecasts. The assimilation of ISCCP-derived surface skin temperature significantly reduced the bias and standard deviation between model predictions and the National Centers for Environmental Prediction (NCEP) reanalysis (Kalnay et al. 1996). However, the assimilation of ISCCP-derived surface skin temperature has a substantial impact on the sensible heat flux, due to an enhanced gradient between the surface and $2 \mathrm{~m}$ air temperatures. If the near-surface air temperature were interactive, as in a coupled land-atmosphere model, then it would respond to this enhanced flux rather than maintaining the artificial temperature gradient. 

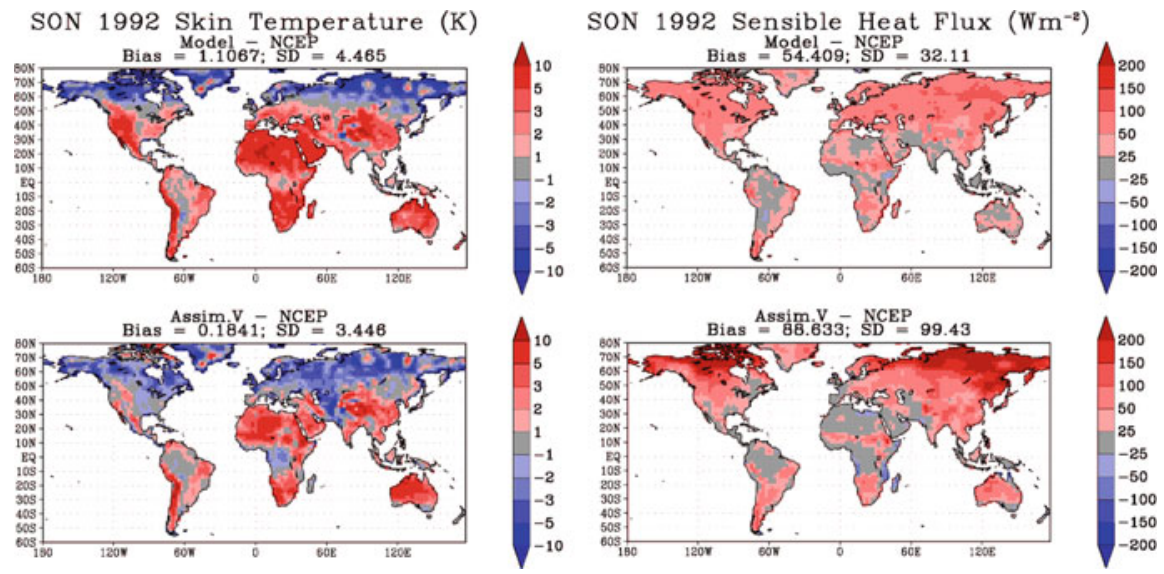

Fig. 9 Differences between simulated and reanalysis (top left), assimilated and reanalysis (bottom left) mean skin temperatures (K), and the resulting differences between simulated and reanalysis (top right), and assimilated and reanalysis (bottom right) mean sensible heat fluxes $\left(\mathrm{Wm}^{-2}\right.$ ) for September-November 1992. Global terrestrial mean bias and standard deviation (SD) for September-November are also noted (Radakovich et al. 2001)

This study was extended by Bosilovich et al. (2007), where remotely sensed surface temperature was assimilated into a coupled atmosphere/land global data assimilation system, with explicit accounting for biases in the model state. In this scheme, an incremental bias correction term is introduced in the model's surface energy budget. The method was validated against the assimilated observations, as well as independent near surface air temperature observations. In many regions, not accounting for the diurnal cycle of bias caused degradation of the diurnal amplitude of background model air temperature. Energy fluxes collected through the Coordinated Enhanced Observing Period (CEOP) were used to more closely inspect the surface energy budget. In general, sensible heat flux is improved with the surface temperature assimilation, and two stations show a reduction of bias by as much as $30 \mathrm{Wm}^{-2}$.

\section{Summary}

Hydrological data assimilation is an objective method to estimate the hydrological system states from irregularly distributed observations. These methods integrate observations into numerical prediction models to develop physically consistent estimates that better describe the hydrological system state than the raw observations alone. This process is extremely valuable for providing initial conditions for hydrological system prediction and/or correcting hydrological system prediction, and for increasing our understanding and improving parametrization of hydrological system behaviour through various diagnostic research studies. 
Hydrological data assimilation has still many open areas of research. Development of hydrological data assimilation theory and methods is needed to: (i) better quantify and use model and observational errors; (ii) create modelindependent data assimilation algorithms that can account for the typical non-linear nature of hydrological models; (iii) optimize data assimilation computational efficiency for use in large operational hydrological applications; (iv) use forward models to enable the assimilation of remote sensing radiances directly; (v) link model calibration and data assimilation to optimally use available observational information; (vi) create multivariate hydrological assimilation methods to use multiple observations with complementary information; (vii) quantify the potential of data assimilation downscaling; and (viii) create methods to extract the primary information content from observations with redundant or overlaying information. Further, the regular provision of snow, soil moisture, and surface temperature observations with improved knowledge of observational errors in time and space are essential to advance hydrological data assimilation. Hydrological models must also be improved to: (i) provide more "observable" land model states, parameters, and fluxes; (ii) include advanced processes such as river runoff and routing, vegetation and carbon dynamics, and groundwater interaction to enable the assimilation of emerging remote sensing products; (iii) have valid and easily updated adjoints; and (iv) have knowledge of their prediction errors in time and space. The assimilation of additional types of hydrological observations, such as streamflow, vegetation dynamics, evapotranspiration, and groundwater or total water storage must be developed.

As with most current data assimilation efforts, we describe data assimilation procedures that are implemented in uncoupled models. However, it is well known that the high-resolution time and space complexity of hydrological phenomena have significant interaction with atmospheric, biogeochemical, and oceanic processes. Scale truncation errors, unrealistic physics formulations, and inadequate coupling between hydrology and the overlying atmosphere can produce feedbacks that can cause serious systematic hydrological errors. Hydrological balances cannot be adequately described by current uncoupled hydrological data systems, because large analysis increments that compensate for errors in coupling processes (e.g. precipitation) result in important non-physical contributions to the energy and water budgets. Improved coupled process models with improved feedback processes, better observations, and comprehensive methods for coupled assimilation are needed to achieve the goal of fully coupled data assimilation systems that should produce the best and most physically consistent estimates of the Earth system.

\section{References}

Andreadis, K.M. and D.P. Lettenmaier, 2006. Assimilating remotely sensed snow observation into a macroscale hydrology model. Adv. Water Resour., 29, 872-886.

Arya, L.M., J.C. Richter and J.F. Paris, 1983. Estimating profile water storage from surface zone soil moisture measurements under bare field conditions. Water Resour. Res., 19, 403-412. 
Aubert, D., C. Loumagne and L. Oudin, 2003. Sequential assimilation of soil moisture and streamflow data into a conceptual rainfall-runoff model. J. Hydrol., 280, 145-161.

Bennett, A.F., 1992. Inverse Methods in Physical Oceanography, Cambridge University Press, Cambridge, 346 pp.

Bergthorsson, P. and B. Döös, 1955. Numerical weather map analysis. Tellus, 7, 329-340.

Bernard, R., M. Vauclin and D. Vidal-Madjar, 1981. Possible use of active microwave remote sensing data for prediction of regional evaporation by numerical simulation of soil water movement in the unsaturated zone. Water Resour. Res., 17, 1603-1610.

Beven, K., 1989. Changing ideas in hydrology: The case of physically-based models. J. Hydrol., 105, 157-172.

Boni, G., D. Entekhabi and F. Castelli, 2001. Land data assimilation with satellite measurements for the estimation of surface energy balance components and surface control on evaporation. Water Resour. Res., 37, 1713-1722.

Bosilovich, M.G., J.D. Radakovich, A.D. Silva, R. Todling and F. Verter, 2007. Skin temperature analysis and bias correction in a coupled land-atmosphere data assimilation system. J. Meteorol. Soc. Jpn., 85A, 205-228.

Bouttier, F. and P. Courtier, 1999. Data assimilation concepts and methods. ECMWF training course notes.

Bouttier, F., J.-F. Mahfouf and J. and Noilhan, 1993. Sequential assimilation of soil moisture from atmospheric low-level parameters. Part I: Sensitivity and calibration studies. J. Appl. Meteorol., 32, 1335-1351.

Bouyssel, F., V. Cassé and J. Pailleux, 1999. Variational surface analysis from screen level atmospheric parameters. Tellus, 51A, 453-468.

Bras, R. and I. Rodriguez-Iturbe,1985. Random Functions and Hydrology, Addison Wesley, Reading, MA, 590 pp.

Bratseth, A.M., 1986. Statistical interpolation by means of successive corrections. Tellus, 38A, 439-447.

Bruckler, L. and H. Witono, 1989. Use of remotely sensed soil moisture content as boundary conditions in soil-atmosphere water transport modeling: 2. Estimating soil water balance. Water Resour. Res., 25, 2437-2447.

Callies, U., A. Rhodin and D. Eppel, 1998. A case study on variational soil moisture analysis from atmospheric observations. J. Hydrol., 212-213, 95-108.

Calvet, J.-C., J. Noilhan and P. Bessemoulin, 1998. Retrieving the root-zone soil moisture from surface soil moisture or temperature estimates: A feasibility study based on field measurements. J. Appl. Meteorol., 37, 371-386.

Caparrini, F., F. Castelli and D. Entekhabi, 2004. Variational estimation of soil and vegetation turbulent transfer and heat flux parameters from sequences of multisensor imagery. Water Resour. Res., 40, W12515.1-W12515.15.

Castelli, F., D. Entekhabi and E. Caporali, 1999. Estimation of surface heat flux and an index of soil moisture using adjoint-state surface energy balance. Water Resour. Res., 35, 3115-3125.

Charney, J.G., M. Halem and R. Jastrow, 1969. Use of incomplete historical data to infer the present state of the atmosphere. J. Atmos. Sci., 26, 1160-1163.

Chen, Y. and D. Zhang, 2006. Data assimilation for transient flow in geologic formations via ensemble Kalman filter. Adv. Water Resour., 29, 1107-1122.

Cosgrove, B.A. and P.R. Houser, 2002. The effect of errors in snow assimilation on land surface modeling. Preprints, 16th Conference on Hydrology, Orlando, FL, American Meteor Society, J136-J137.

Cressman, G.P., 1959. An operational objective analysis system. Mon. Weather Rev., 87, 367-374.

Crosson, W.L., C.A. Laymon, R. Inguva and M.P. Schamschula, 2002. Assimilating remote sensing data in a surface flux-soil moisture model. Hydro. Processes, 16, 1645-1662.

Crow, W., 2003. Correcting land surface model predictions for the impact of temporally sparse rainfall rate measurements using an ensemble Kalman filter and surface brightness temperature observations. J. Hydrometeorol., 4, 960-973. 
Crow, W.T. and E. van Loon, 2006. Impact of incorrect model error assessment on the sequential assimilation of remotely sensed surface soil moisture. J. Hydrometeorol., 7, 421-432.

Crow, W.T. and E.F. Wood, 2003. The assimilation of remotely sensed soil brightness temperature imagery into a land surface model using ensemble Kalman filtering: A case study based on ESTAR measurements during SGP97. Adv. Water Resour., 26, 137-149.

Daley, R., 1991. Atmospheric Data Analysis, Cambridge University Press, Cambridge, 460 pp.

Dee, D.P. and A. da Silva, 1998. Data assimilation in the presence of forecast bias. Q. J.R. Meteorol. Soc., 124, 269-295.

Dee, D.P. and R. Todling, 2000. Data assimilation in the presence of forecast bias: The GEOS moisture analysis. Mon. Weather Rev., 128, 3268-3282.

De Lannoy, G.J.M., P.R. Houser, V.R.N. Pauwels and N.E.C. Verhoest, 2006. Assessment of model uncertainty for soil moisture through ensemble verification. J. Geophys. Res., 111, D10101.1D10101.18.

De Lannoy, G.J.M., P.R. Houser, V.R.N. Pauwels and N.E.C. Verhoest, 2007a. State and bias estimation for soil moisture profiles by an ensemble Kalman filter: Effect of assimilation depth and frequency. Water Resour. Res., 43, W06401, doi:10.1029/2006WR005100.

De Lannoy, G.J.M., P.R. Houser, N.E.C. Verhoest and V.R.N. Pauwels, 2009. Adaptive soil moisture profile filtering for horizontal information propagation in the independent column-based CLM2.0. J. Hydrometeorol., 10, 766-779.

De Lannoy, G.J.M., R.H. Reichle, P.R. Houser, K.R. Arsenault, V.R.N. Pauwels and N.E.C. Verhoest, 2010. Satellite-scale snow water equivalent assimilation into a high-resolution land surface model. J. Hydrometeorol., 11, 352-369, doi:10.1175/2009JHM1194.1.

De Lannoy, G.J.M., R.H. Reichle, P.R. Houser, V.R.N. Pauwels and N.E.C. Verhoest, 2007b. Correcting for forecast bias in soil moisture assimilation with the ensemble Kalman filter. Water Resour. Res., 43, W09410, doi:10.1029/2006WR00544.

Déry, S.J., V.V. Salomonson, M. Stieglitz, D.K. Hall and I. Appel, 2005. An approach to using snow areal depletion curves inferred from MODIS and its application to land surface modelling in Alaska. Hydrol. Processes, 19, 2755-2774.

Dirmeyer, P., 2000. Using a global soil wetness dataset to improve seasonal climate simulation. $J$. Climate, 13, 2900-2921.

Dong, J., J.P. Walker and P.R. Houser, 2005. Factors affecting remotely sensed snow water equivalent uncertainty. Remote Sens. Environ., 97, 68-82, doi:10.1016/j.rse.2005.04.010.

Dong, J., J.P. Walker, P.R. Houser and C. Sun, 2007. Scanning multichannel microwave radiometer snow water equivalent assimilation. J. Geophys. Res., 112, D07108, doi:10.1029/2006JD007209.

Douville, H., P. Viterbo, J.-F. Mahfouf and A.C.M. Beljaars, 2000. Evaluation of the optimum interpolation and nudging techniques for soil moisture analysis using fife data. Mon. Weather Rev., 128, 1733-1756.

Duan, Q., S. Sorooshian and V.K. Gupta, 1992. Effective and efficient global optimization for conceptual rainfall-runoff models. Water Resour. Res., 28, 1015-1031.

Dunne, S. and D. Entekhabi, 2005. An ensemble-based reanalysis approach to land data assimilation. Water Resour. Res., 41, W02013.1-W02013.18.

Dunne, S. and D. Entekhabi, 2006. Land surface state and flux estimation using the ensemble Kalman smoother during the Southern Great Plains 1997 field experiment. Water Resour. Res., 42, W01407.1-W01407.15.

Durand, M. and S.A. Margulis, 2006. Feasibility test of multifrequency radiometric data assimilation to estimate snow water equivalent. J. Hydrometeorol., 7, 443-457.

Durand, M. and S.A. Margulis, 2007. Correcting first-order errors in snow water equivalent estimates using a multifrequency, multiscale radiometric data assimilation scheme. J. Geophys. Res., 112, D13121.1-D13121.15.

Durand, M. and S.A. Margulis, 2008. Effects of uncertainty magnitude and accuracy on assimilation of multiscale measurements for snowpack characterization. J. Geophys. Res., 113, D02105.1-D02105.17. 
Eigbe, U., M. Beck, H. Weather and F. Hirano, 1998. Kalman filtering in groundwater flow modelling: Problems and prospects. Stochast. Hydrol. Hydraul., 12, 15-32.

Entekhabi, D., H. Nakamura and E.G. Njoku, 1994. Solving the inverse problem for soil moisture and temperature profiles by sequential assimilation of multifrequency remotely sensed observations. IEEE Trans. Geosci. Rem. Sens., 32, 438-448.

Evensen, G., 1994. Sequential data assimilation with a nonlinear quasi-geostrophic model using Monte Carlo methods to forecast error statistics. J. Geophys. Res., 99, 10143-10162.

Evensen, G., 2003. The ensemble Kalman filter: Theoretical formulation and practical implementation. Ocean Dyn., 53, 343-367.

Francois, C., A. Quesney and C. Ottlé, 2003. Sequential assimilation of ERS-1 SAR data into a coupled land surface-hydrological model using an extended Kalman filter. J. Hydrometeorol., 4, 473-487.

Friedland, B., 1969. Treatment of bias in recursive filtering. IEEE Trans. Autom. Control, AC-14, 359-367.

Galantowicz, J.F., D. Entekhabi and E.G. Njoku, 1999. Tests of sequential data assimilation for retrieving profile soil moisture and temperature from observed L-band radiobrightness. IEEE Trans. Geosci. Rem. Sens., 37, 1860-1870.

Georgakakos, K.P. and O.W. Baumer, 1996. Measurement and utilization of on-site soil moisture data. J. Hydrol., 184, 131-152.

Gove, J.H. and D.Y. Hollinger, 2006. Application of a dual unscented Kalman filter for simultaneous state and parameter estimation in problems of surface atmosphere exchange. J. Geophys. Res., 111, D08S07.1-D08S07.21.

Heathman, G., P. Starks, L. Ahuj and T. Jackson, 2003. Assimilation of soil moisture to estimate profile soil water content. J. Hydrol., 279, 1-17.

Hebson, C. and E. Wood, 1985. Partitioned state and parameter estimation for real-time flood forecasting. Appl. Math. Comput., 17, 357-374.

Hess, R., 2001. Assimilation of screen-level observations by variational soil moisture analysis. Meteorol. Atmos. Phys., 77, 145-154.

Hoeben, R. and P.A. Troch, 2000. Assimilation of active microwave observation data for soil moisture profile estimation. Water Resour. Res., 36, 2805-2819.

Hollingsworth, A. and P. Lönnberg, 1989. The verification of objective analyses: Diagnostics of analysis system performance. Meteorol. Atmos. Phys., 40, 3-27.

Houser, P., M.F. Hutchinson, P. Viterbo, J. Hervé Douville and S.W. Running, 2004. Terrestrial data assimilation, Chapter C.4. In Vegetation, Water, Humans and the Climate, Global Change - The IGB Series, Kabat, P. et al. (eds.), Springer, Berlin, pp 273-287.

Houser, P.R., W.J. Shuttleworth, J.S. Famiglietti, H.V. Gupta, K.H. Syed and D.C. Goodrich, 1998. Integration of soil moisture remote sensing and hydrologic modeling using data assimilation. Water Resour. Res., 34, 3405-3420.

Houtekamer, P.L. and H.L. Mitchell, 1998. Data assimilation using a Ensemble Kalman filter techniques. Mon. Weather Rev., 126, 796-811.

$\mathrm{Hu}$, Y., X. Gao, W. Shuttleworth, H. Gupta and P. Viterbo, 1999. Soil moisture nudging experiments with a single column version of the ECMWF model. Q. J. R. Meteorol. Soc., 125, 1879-1902.

Hurkmans, R., C. Paniconi and P.A. Troch, 2006. Numerical assessment of a dynamical relaxation data assimilation scheme for a catchment hydrological model. Hydrol. Processes, 20, 549-563.

Jackson, T.J., T.J. Schmugge, A.D. Nicks, G.A. Coleman and E.T. Engman, 1981. Soil moisture updating and microwave remote sensing for hydrological simulation. Hydrol. Sci. Bull., 26, 305-319.

Jazwinski, A.H., 1970. Stochastic Processes and Filtering Theory, Vol. 64. Academic Press, New York, $376 \mathrm{pp}$.

Kalman, R.E., 1960. A new approach to linear filtering and prediction problems. Trans. ASME, Ser. D, J. Basic Eng., 82, 35-45. 
Kalnay, E., M. Kanamitsu, R. Kistler, et al., 1996. The NCEP/NCAR 40-year reanalysis project. Bull. Amer. Meteorol. Soc., 77, 437-471.

Katul, G.G., O. Wendroth, M.B. Parlange, C.E. Puente, M.V. Folegatti and D.R. Nielsen, 1993. Estimation of in situ hydraulic conductivity function from nonlinear filtering theory. Water Resour. Res., 29, 1063-1070.

Komma, J., G. Blöschl and C. Reszler, 2008. Soil moisture updating by ensemble Kalman filtering in real-time flood forecasting. J. Hydrol., 357, 228-242.

Koster, R.D., M. Suarez, P. Liu, U. Jambor, A. Berg, M. Kistler, R. Reichle, M. Rodell and J. Famiglietti, 2004. Realistic initialization of land surface states: Impacts on subseasonal forecast skill. J. Hydrometeorol., 5, 1049-1063.

Kostov, K.G. and T.J. Jackson, 1993. Estimating profile soil moisture from surface layer measurements - A review. In: Proceedings of the International Society for Optical Engineering, Vol. 1941. Orlando, FL, pp 125-136.

Kumar, P. and A.L. Kaleita, 2003. Assimilation of near-surface temperature using extended Kalman filter. Adv. Water Resour., 26, 79-93.

Lakshmi, V., 2000. A simple surface temperature assimilation scheme for use in land surface models. Water Resour. Res., 36, 3687-3700.

$\mathrm{Li}, \mathrm{J}$. and S. Islam, 1999. On the estimation of soil moisture profile and surface fluxes partitioning from sequential assimilation of surface layer soil moisture. J. Hydrol., 220, 86-103.

Li, J. and S. Islam, 2002. Estimation of root zone soil moisture and surface fluxes partitioning using near surface soil moisture measurements. J. Hydrol., 259, 1-14.

Lorenc, A., 1981. A global three-dimensional multivariate statistical interpolation scheme. Mon. Weather Rev., 109, 701-721.

Lorenc, A.C., R.S. Bell and B. Macpherson, 1991. The meteorological office analysis correction data assimilation scheme. Q. J. R. Meteorol. Soc., 117, 59-89.

Mahfouf, J.-F., 1991. Analysis of soil moisture from near-surface parameters: A feasibility study. J. Appl. Meteorol., 30, 1534-1547.

Mahfouf, J. and P. Viterbo, 2001. Land surface assimilation. Meteorological Training Course Lecture Series ECMWF.

Margulis, S.A., D. McLaughlin, D. Entekhabi and S. Dunne, 2002. Land data assimilation of soil moisture using measurements from the Southern Great Plains 1997 field experiment. Water Resour. Res., 38, 35.1-35.18.

Margulis, S.A., E.F. Wood and P.A. Troch, 2006. A terrestrial water cycle: Modeling and data assimilation across catchment scales. J. Hydrometeorol., 7, 309-311.

Maybeck, P.S., 1979. Stochastic Models, Estimation, and Control, Vol. 1 (Vol. 141). Academic Press, Toronto, $423 \mathrm{pp}$.

McLaughlin, D., 1995. Recent developments in hydrologic data assimilation. In U.S. National Report to the IUGG (1991-1994). Rev. Geophys., 33(supplement), 977-984.

McLaughlin, D., 2002. An integrated approach to hydrologic data assimilation: Interpolation, smoothing, and filtering. Adv. Water Resour., 25, 1275-1286.

Milly, P.C.D., 1986. Integrated remote sensing modelling of soil moisture: Sampling frequency, response time, and accuracy of estimates. Integrated Design of Hydrological Networks Proceedings of the Budapest Symposium, IAHS Publication No. 158, 201-211.

Milly, P. and Z. Kabala, 1986. Integrated modelling and remote sensing of soil moisture. In Hydrologic applications of space technology - Proceedings of the Cocoa Beach Workshop, Vol. 158. Florida, pp 201-211.

Montaldo, N. and J.D. Albertson, 2003. Multi-scale assimilation of surface soil moisture for robust root zone moisture predictions. Adv. Water Resour., 26, 33-44.

Montaldo, N., J.D. Albertson, M. Mancini and G. Kiely, 2001. Robust simulation of root zone soil moisture with assimilation of suface soil moisture data. Water Resour. Res., 37, 2889-2900.

Moradkhani, H., S. Sorooshian, H.V. Gupta and P.R. Houser, 2005. Dual state-parameter estimation of hydrological models using ensemble Kalman filter. Adv. Water Resour., 28, 135-147.

Nichols, N.K., 2001. State estimation using measured data in dynamic system models, Lecture notes for the Oxford/RAL Spring School in Quantitative Earth Observation. 
Ottlé, C. and D. Vidal-Madjar, 1994. Assimilation of soil moisture inferred from infrared remote sensing in a hydrological model over the HAPEX-MOBILHY Region. J. Hydrol., 158, 241-264.

Oudin, L., A. Weisse, C. Loumage and S. Le Hégarat-Mascle, 2003. Assimilation of soil moisture into hydrological models for flood forecasting: A variational approach. Can. J. Rem. Sens., 29, 679-686.

Pan, M. and E.F. Wood, 2006. Data assimilation for estimating the terrestrial water budget using a constrained ensemble Kalman filter. J. Hydrometeorol., 7, 534-547.

Paniconi, C., M. Marrocu, M. Putti and M. Verbunt, 2003. Newtonian nudging for a Richards equation-based distributed hydrological model. Adv. Water Resour., 26, 161-178.

Parrish, D. and J. Derber, 1992. The national meteorological center's spectral statistical interpolation analysis system. Mon. Weather Rev., 120, 1747-1763.

Pathmathevan, M., T. Koike, X. Lin and H. Fujii, 2003. A simplified land data assimilation scheme and its application to soil moisture experiments in 2002 (SMEX02). Water Resour. Res., 39, SWC6.1-SWC6.20.

Pauwels, V.R.N. and G.J.M. De Lannoy, 2006. Improvement of modeled soil wetness conditions and turbulent fluxes through the assimilation of observed discharge. J. Hydrometeorol., 7, 458-477.

Pauwels, V.R.N., R. Hoeben, N.E.C. Verhoest and F.P. De Troch, 2001. The importance of the spatial patterns of remotely sensed soil moisture in the improvement of discharge predictions for small-scale basins through data assimilation. J. Hydrol., 251, 88-102.

Pauwels, V.R.N., N.E.C. Verhoest, G.J.M. De Lannoy, V. Guissard, C. Lucau and P. Defourny, 2007. Optimization of a coupled hydrology/crop growth model through the assimilation of observed soil moisture and LAI values using an Ensemble Kalman Filter. Water Resour. Res., 43, W04421, doi:10.1029/2006WR004942.

Pleim, J.E. and A. Xiu, 2003. Development of a land surface model. Part II: Data assimilation. J. Appl. Meteorol., 42, 1811-1822.

Porter, D., B. Gibbs, W. Jones, P. Huyakorn, L. Hamm and G. Flach, 2000. Data fusion modeling for groundwater systems. J. Contam. Hydrol., 42, 303-335.

Prevot, L., R. Bernard, O. Taconet, et al., 1984. Evaporation from a bare soil evaluated using a soil water transfer model and remotely sensed surface soil moisture data. Water Resour. Res., 20 , 311-316.

Radakovich, J.D., P.R. Houser, A. da Silva and M.G. Bosilovich, 2001. Results from global landsurface data assimilation methods. Proceedings AMS 5th Symposium on Integrated Observing Systems, Albuquerque, NM, 14-19 January, pp 132-134.

Reichle, R.H., W.T. Crow and C.L. Keppenne, 2008. An adaptive ensemble Kalman filter for soil moisture data assimilation, Water Resour. Res., 44, W03423, doi:10.1029/2007WR006357.

Reichle, R.H., D. Entekhabi and D.B. McLaughlin, 2001. Downscaling of radiobrightness measurements for soil moisture estimation: A four-dimensional variational data assimilation approach. Water Resour. Res., 37, 2353-2364.

Reichle, R.H. and R. Koster, 2003. Assessing the impact of horizontal error correlations in background fields on soil moisture estimation. J. Hydrometeorol., 4, 1229-1242.

Reichle, R.H. and R. Koster, 2004. Bias reduction in short records of satellite soil moisture. Geophys. Res. Lett., 31, L19501.1-L19501.4.

Reichle, R.H. and D.B. McLaughlin, 2001. Variational data assimilation of microwave radiobrightness observations for land surface hydrologic applications. IEEE Trans. Geosci. Rem. Sens., 39, 1708-1718.

Reichle, R.H., D.B. McLaughlin and D. Entekhabi, 2002a. Hydrologic data assimilation with the ensemble Kalman filter. Mon. Weather Rev., 120, 103-114.

Reichle, R.H., J.P. Walker, P.R. Houser and R.D. Koster, 2002b. Extended versus ensemble Kalman filtering for land data assimilation. J. Hydrometeorol., 3, 728-740.

Rhodin, A., F. Kucharski, U. Callies, D. Eppel and W. Wergen, 1999. Variational analysis of effective soil moisture from screen-level atmospheric parameters: Application to a short-range weather forecast model. Q. J. R. Meteorol. Soc., 125, 2427-2448. 
Rodell, M. and P.R. Houser, 2004. Updating a land surface model with MODIS-derived snow cover. J. Hydrometeorol., 5, 1064-1075.

Rood, R.B., S.E. Cohn and L. Coy, 1994. Data assimilation for EOS: The value of assimilated data, Part 1. Earth Observer, 6, 23-25.

Rüdiger, C., G. Hancock, H.M. Hemakumara, B. Jacobs, J.D. Kalma, C. Martinez, M. Thyer, J.P. Walker, T. Wells and G.R. Willgoose, 2007. The Goulburn River experimental catchment data set. Water Resour. Res., 43, W10403, doi:10.1029/2006WR005837.

Rüdiger, C., J.P. Walker, J.D. Kalma, G.R. Willgoose and P.R. Houser, 2005. Root zone soil moisture retrieval using streamflow and surface soil moisture data assimilation. In MODSIM 2005 International Congress on Modelling and Simulation, Zerger, A. and Argent, R.M. (eds.), Modelling and Simulation Society of Australia and New Zealand, Inc., Melbourne, Australia, 12-15 December, 2005, pp 1458-1464.

Schuurmans, J., P. Troch, A. Veldhuizen, W. Bastiaansen and M. Bierkens, 2003. Assimilation of remotely sensed latent heat flux in a distributed hydrological model. Adv. Water Resour., 26, $151-159$.

Seuffert, G., H. Wilker, P. Viterbo, M. Drusch and J.-F. Mahfouf, 2004. The usage of screen-level parameters and microwave brightness temperature for soil moisture analysis. J. Hydrometeorol., 5, 516-531.

Slater, A.G. and M. Clark, 2006. Snow data assimilation via an ensemble Kalman filter. J. Hydrometeorol., 7, 478-493.

Stauffer, D.R. and N.L. Seaman, 1990. Use of four-dimensional data assimilation in a limitedarea mesoscale model. Part I: Experiments with synoptic-scale data. Mon. Weather Rev., 118, $1250-1277$.

Stieglitz, M., D. Rind, J. Famiglietti and C. Rosenzweig, 1997. An efficient approach to modeling the topographic control of surface hydrology for regional and global climate modeling. J. Climate, 10, 118-137.

Sun, C., J.P. Walker and P.R. Houser, 2004. A methodology for snow data assimilation in a land surface model. J. Geophys. Res., 109, D08108.1-D08108.12.

Thiemann, M., M. Trosset, H. Gupta and S. Sorooshian, 2001. Bayesian recursive parameter estimation for hydrological models. Water Resour. Res., 37, 2521-2535.

Turner, M.R.J., J.P. Walker and P.R. Oke, 2007. ensemble member generation for sequential data assimilation. Remote Sens. Environ., 112, doi:10.1016/j.rse.2007.02.042.

van Loon, E.E. and P.A. Troch, 2001. Directives for 4-D soil moisture data assimilation in hydrological modelling. IAHS, 270, 257-267.

Viterbo, P. and A. Beljaars, 1995. An improved land surface parameterization scheme in the ECMWF model and its validation. J. Climate, 8, 2716-2748.

Vrugt, J.A., H.V. Gupta, B. O'Nualláin and W. Bouten, 2006. Real-time data assimilation for operational ensemble streamflow forecasting. J. Hydrometeorol., 7, 548-565.

Walker J.P. and P.R. Houser, 2001. A methodology for initialising soil moisture in a global climate model: Assimilation of near-surface soil moisture observations. J. Geophys. Res., 106, 11761-11774.

Walker, J.P. and P.R. Houser, 2004. Requirements of a global near-surface soil moisture satellite mission: Accuracy, repeat time, and spatial resolution. Adv. Water Resour, 27, 785-801.

Walker, J.P. and P.R. Houser, 2005. Hydrologic data assimilation. In Advances in Water Science Methodologies, Aswathanarayana, A. (ed.), A.A. Balkema, The Netherlands, 230 pp.

Walker, J.P., P.R. Houser and R. Reichle, 2003. New technologies require advances in hydrologic data assimilation. EOS, 84, 545-551.

Walker, J.P., G.R. Willgoose and J.D. Kalma, 2001a. One-dimensional soil moisture profile retrieval by assimilation of near-surface observations: A comparison of retrieval algorithms. Adv. Water Resour, 24, 631-650.

Walker, J.P., G.R. Willgoose and J.D. Kalma, 2001b. One-dimensional soil moisture profile retrieval by assimilation of near-surface measurements: A simplified soil moisture model and field application. J. Hydrometeorol., 2, 356-373. 
Walker, J.P., G.R. Willgoose and J.D. Kalma, 2002. Three-dimensional soil moisture profile retrieval by assimilation of near-surface measurements: Simplified Kalman filter covariance forecasting and field application. Water Resour. Res., 38, 1301, doi:10.1029/2002WR001545.

Wendroth, O., H. Rogasik, S. Koszinski, C.J. Ritsema, L.W. Dekker and D.R. Nielsen, 1999. Statespace prediction of field-scale soil water content time series in a sandy loam. Soil \& Till. Res., 50, 85-93.

Wilker, H., M. Drusch, G. Seuffert and C. Simmer, 2006. Effects of the near-surface soil moisture profile on the assimilation of L-band microwave brightness temperature. J. Hydrometeorol., 7, 433-442.

Wingeron, J.-P., A. Olioso, J.-C. Calvet and P. Bertuzzi, 1999. Estimating root zone soil moisture from surface soil moisture data and soil-vegetation-atmosphere transfer modeling. Water Resour. Res., 35, 3735-3745.

WMO, 1992. Simulated real-time intercomparison of hydrological models (Tech. Rep. No. 38). Geneva.

Zaitchik, B.F., M. Rodell and R. Reichle, 2008. Assimilation of GRACE terrestrial water storage data into a land surface model: Results for the Mississippi river basin. J. Hydrometeorol., 9, $535-548$.

Zhang, H. and C.S. Frederiksen, 2003. Local and nonlocal impacts of soil moisture initialization on AGCM seasonal forecasts: A model sensitivity study. J. Climate, 16, 2117-2137. 